Article

\title{
Assessing the Land and Vegetation Cover of Abandoned Fire Hazardous and Rewetted Peatlands: Comparing Different Multispectral Satellite Data
}

\author{
Andrey Sirin ${ }^{1, *}$, Maria Medvedeva ${ }^{1}$, Alexander Maslov ${ }^{1}$ and Anna Vozbrannaya ${ }^{2}$ \\ 1 Institute of Forest Science, Russian Academy of Sciences, Moscow Region, 143030 Uspenskoye, Russia; \\ eveeza@yandex.ru (M.M.); am-pyrola@mail.ru (A.M.) \\ 2 Meschera State National Park, Ministry of Natural Resources of Russian Federation, Vladimir Oblast, \\ 601500 Gus-Khrustalny, Russia; nucifraga@rambler.ru \\ * Correspondence: sirin@ilan.ras.ru; Tel./Fax: +7-495-634-5257
}

Received: 13 April 2018; Accepted: 1 June 2018; Published: 5 June 2018

\begin{abstract}
Since the 1990s, many peatlands that were drained for peat extraction and agriculture in Russia have been abandoned with high $\mathrm{CO}_{2}$ emissions and frequent fires, such as the enormous fires around Moscow in 2010. The fire hazard in these peatlands can be reduced through peatland rewetting and wetland restoration, so monitoring peatland status is essential. However, large expanses, poor accessibility, and fast plant succession pose as challenges for monitoring these areas without satellite images. In this study, a technique involving multispectral satellite data was used to identify six land cover classes that meet the requirements for peatland monitoring using the Meschera National Park as the testing area. This park is the largest area of once-exploited and now rewetted peatlands. However, data from one scanner are often insufficient to successfully implement this technique. In this study, we compared the land cover classifications obtained by using data from Spot-5, Spot-6, Landsat-7, Landsat-8, and Sentinel-2 satellites. The Spot-6 data were insufficient, despite having a higher spatial resolution, due to the lack of a shortwave infrared (SWIR) band. The high classification accuracy attained using data from other sensors enabled their combined use to provide an acceptable accuracy in the final product. The classification results were compared using minimum distance Erdas Imagine and the object-oriented ScanEx Image Processor, and the classification accuracy was similar between satellite images, which facilitates the transition from one method to another without quality loss. The proposed and tested approach can be used to analyze the status of abandoned and rewetted peatlands in other locations for the inventory and prioritization of sites for rewetting and restoration, monitoring status changes, and assessing restoration efficacy. The comparability of the data from different sensors allows for the combination of classified images and creates new possibilities for time series analysis.
\end{abstract}

Keywords: remote sensing; multispectral images; peat extraction lands; vegetation cover; peat fires; rewetting

\section{Introduction}

Peatlands are wetland ecosystems characterized by the accumulation of organic matter (peat) derived from dead and decaying plant material under high water saturation [1,2]. The water, plants, and peat in peatlands are strongly interconnected. If any of these components are altered, the nature of the peatland changes. Being found in almost all geographical areas, peatlands are especially abundant in areas such as the boreal regions of Canada, Sweden, Finland, and Eastern European countries, including Russia [2]. Even though peatlands occupy only 3\% of the earth's surface [3], peatlands are important for the environment as they play a key regulating role inmany natural 
processes [1]. Peatlands are the most efficient terrestrial ecosystem in terms of carbon storage; however, they are a growing source of greenhouse gas (GHG) emissions after degradation [2,4-6]. Degradation of drained peatlands and peat fires are important sources of greenhouse gases that contribute to climate change [7]. Therefore, the rewetting of unused drained peatlands and mire restoration are recognized as the most important measures to re-establish a range of mire ecosystem services, including their contribution to climate stability $[3,8,9]$ and biological diversity [10-12]. Covering less than $0.3 \%$ of the earth's surface, drained peatlands produce $5 \%$ of the global carbon dioxide $\left(\mathrm{CO}_{2}\right)$ emissions [13].

Peatlands cover over $8 \%$ of Russia's land surface, and combined with shallow peat lands, account for over one-fifth of Russia's territory [14-16]. In some regions such as northern European Russia or West Siberia, peatlands are more than one-third of the land surface [17]. Russia contains a considerable proportion of Europe's peatlands [18]. However, the peatlands in central, western, and northwestern European Russia have been considerably transformed by human economic activities throughdrainage for peat extraction, agriculture, and forestry $[19,20]$. A total of 850,000 to $1,500,000$ ha of mires were affected by peat extraction in Russia throughout the 20th century $[17,20]$. Peat extraction, especially if completed by milling, which is the most common industrial peat production method [5], has had the greatest impact on peatlands. Wet extraction methods such as excavation leave behind waterlogged pits that gradually turn to mires. In comparison, milling involves intensive drainage of the production field, which may be used continuously for 15 or more years. Previously, peat deposits had to be re-cultivated for farming, forestry, etc. However, the non-recultivated cutover peatlands have continued to increase with the output of peat, reaching a peak in the 1970s and 1980s. By the early 1990s, some 250,000 ha were still being exploited, primarily using the milling method [17]. Later, with economic changes and the decline in the peat industry, large areas of half-depleted milling fields were abandoned without re-cultivation.

Abandoned drained peatlands are inhospitable for plants, given the intensive degradation, water and wind erosion, and peat decomposition with emissions of carbon dioxide into the atmosphere. The probability of peat fires is highest in these areas [21,22], including in the boreal and other climatic zones of the country [23]. Fires could occur more frequently due to climate change [10]. The fires are mostly concentrated in central European Russia, with the most fires and highest fire hazard in the Moscow region, evidenced by the severe peat fires in 2002 and 2010 [22,24]. Abandoned peatlands that were drained for peat extraction or agriculture have become the most acute peatland-related environmental problem in the country [20], contributing to climate change progress $[2,10]$, placing Russia among the countries with the highest $\mathrm{CO}_{2}$ emissions from these sources [13].

Rewetting could return peatlands to a waterlogged state, which reduces the risk of fires and peat oxidation [3], and initiates the mire restoration process. The prevention of peat fires is the main driver of peatland restoration in Russia [22]. After the extensive fires in 2010, Moscow Province implemented the northern hemisphere's most ambitious rewetting project for over 70,000 ha of fire hazardous peatlands from 2010-2013 [25]. However, hundreds of thousands of hectares of abandoned peatlands remain. Reasonable methods are needed to assess and monitor the peatland condition and fire hazard status, to support restoration prioritization, and to test the effectiveness of rewetting and restoration measures.

Degraded peatlands often cover large areas (hundreds to thousands of hectares), are scattered, difficult to access, and are characterized by multi-speed land and vegetation cover dynamics. Rewetting triggers the restoration succession of vegetation with more pronounced fluctuations and spatial differences. To assess the effectiveness of mire restoration, which could take years, long-term monitoring is required. Only multispectral satellite remote sensing data (RSD) can meet these requirements and provide an assessment of the area with a frequency of at least one to two times over the summer period.

Various remote sensing data (RSD) have been used in wetland research [26,27], including multispectral RSD. Specific features in multispectral RSD have been used for wetland assessment, including high spectral 
and spectral variability, and the influence of water on the spectral characteristics of vegetation and their temporal changes $[28,29]$. These specific features are related to human-disturbed rewetted and restored peatlands. However, few studies have addressed this use of data [30-32].

Previously, we developed and tested the classification of land and vegetation cover that allows the assessment of the potential fire hazard of a peatland area, as well as changes after rewetting and restoration, based on Landsat-5 TM and Landsat-7 ETM+ data [33], and which has been used to monitor different human-disturbed and restored peatlands [22]. However, while monitoring groups of peatlands within a larger territory, it was found that they were rarely covered by one type of remote sensing data (RSD) source and thus acombination of RSD from different scanners is required. The ability to cover studied territory also depends on the swath width of using RSD, e.g., the swath width for Landsat- $5,-7$, and -8 is $185 \mathrm{~km}$; for Sentinel-2, it is $290 \mathrm{~km}$; and for Spot- $4,-5,-6$, and-7, it is much lower, with a figure of $60 \mathrm{~km}$. Furthermore, the effects of rewetting and restoration measures do not occur immediately (vegetation successions occur over the years), meaning that long-term monitoring is required, which is not possible with data from only one satellite as some satellites may cease to operate, and others are introduced. The use of several satellites provides the best temporal area coverage of the territory. The freely available RSD are limited by the satellite revisit period, imaging time, and cloud cover. Therefore, using ordered on-demand commercial RSD is often necessary and in some cases, could be critically important for regular monitoring.

The goal of this paper was to explore what could be achieved using freely available imagery from Landsat-7 ETM+, Landsat-8 OLI, Sentinel-2A MSI, and commercial satellite data from Spot-5 HRG and Spot-6 HRG for the monitoring of abandoned peat extraction sites with a focus on the assessment of peatlands status, and on the analyses of changes that occur as a result of rewetting and mire restoration, as well as how to provide a link between different RSD for the analysis of temporal changes and for large territories when one source of data is not enough for this task.

\section{Materials and Methods}

\subsection{Study Area}

The study was performed at several sites in the Meschera National Park (NP). The park was established in 1992 in the Gus-Khrustalny administrative district in the Vladimir Province at the eastern border with the Moscow Province (Figure 1a). Covering an area of 118,700 ha, the park has a wide range of mire ecosystems typical of the Meschera Lowland, including 62 large mire and peatland complexes. Located within the park's boundaries is one of the largest peatland complexes in European Russia disturbed by peat extraction that occurred at different times with the use of various extraction technologies (Figure 1b), including the milled peat method [33]. Due to frequent forest and peat fires, the NP started to pioneer large-scale peatland-rewetting in Russia to restore mire ecosystems [22].

Vegetation of natural and human-disturbed peatlands in the NP has been comprehensively studied [34,35]. Digital maps of some abandoned peat extraction sites are available, which allowed for the compilation of a set of benchmark data for the identification of land cover classes. Vegetation cover and environmental indicators have been monitored since 2005 on permanent plots of the three most representative peatland complexes: Tasinskoye, Ostrovskoye, and Garinskoye. Major trends and factors of vegetation dynamics have been identified for disturbed peatlands [36]. Eight test sites (disturbed peatlands) with a total area of 8000 ha (Figure 1b, 2: 8 test sites in the National Park), located in different peatland complexes within the NP, were used in this study. 


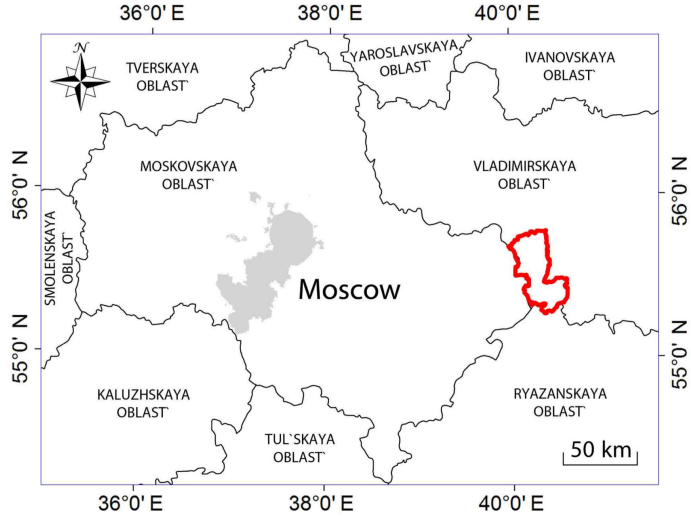

(a)

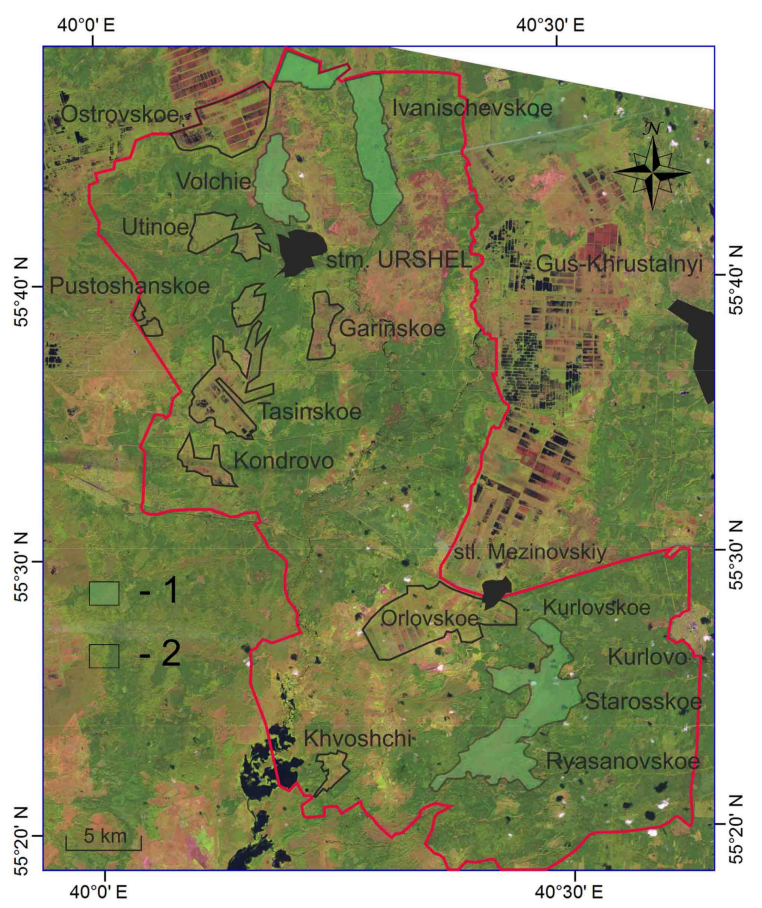

(b)

Figure 1. Meschera National Park in Vladimir Province, Russia. (a) Location of Meschera National Park shown in red; and (b) 1: mire complexes and 2: test sites (eight peatland complexes) in the National Park.

\subsection{Satellite Source Data}

We analyzed five sets of multispectral high spatial resolution data as Landsat-7 (L1T), Spot-5 (L2), and Spot-6 (L2), Landsat-8 (L1T), and Sentinel-2 (L1C) (Table 1). The source of the data from Landsat-7, Landsat-8, and Sentinel-2 is the United States Geological Survey (USGS). The source of the data from Spot- 5 and Spot- 6 is the ScanEx R\&D Center. For an accurate comparison, we attempted to find cloud-free and haze-free data from different scanners for periods that overlapped as much as possible.

Table 1. Characteristics of satellite data used.

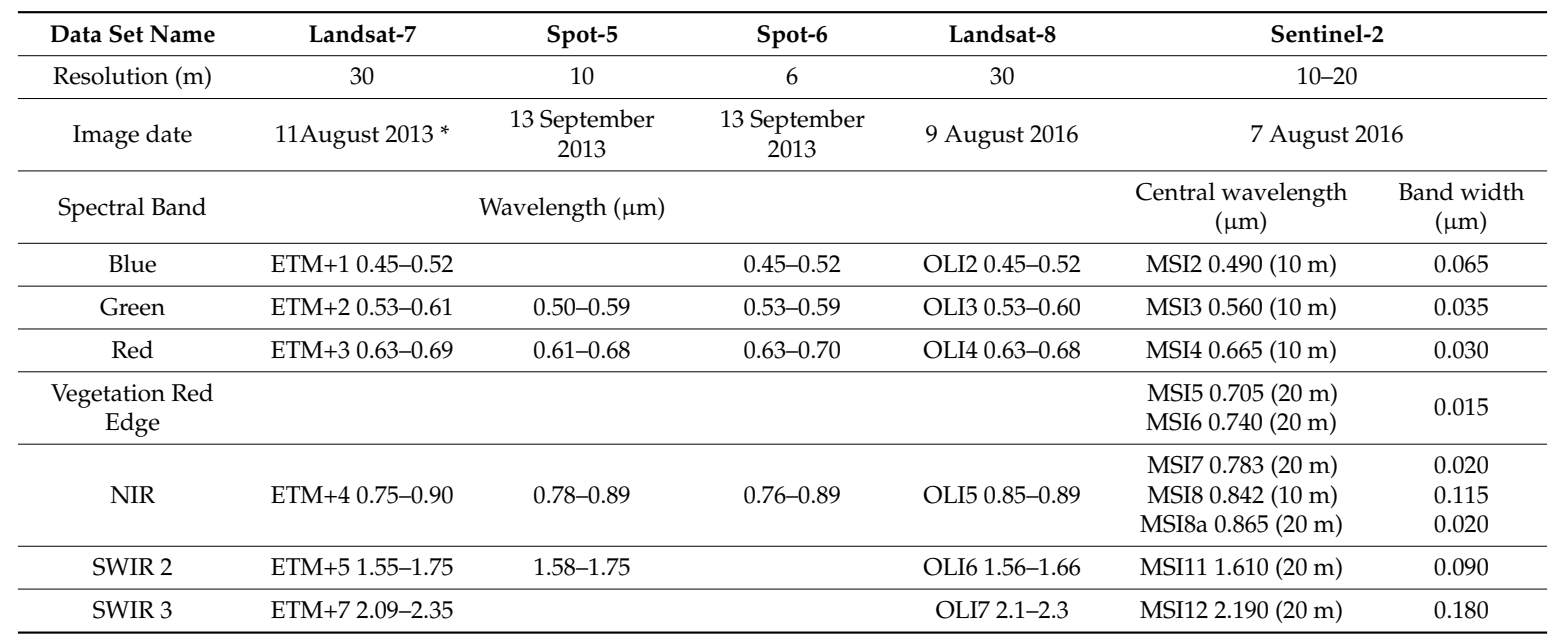

Note: * mostly the scene from 11 August 2013 and, to a lesser degree, from 1 July 2013.

Data for the same day (13 September 2013) were obtained from Spot-5 and Spot-6. For Landsat-7, we used two scenes dated 1 July 2013 and 11 August 2013. Data for other mutually closer dates were 
either unavailable or unusable due to cloud cover. For 2016, the RSD data were available for Landsat-8 (9 August 2016) and for Sentinel-2 (7 August 2016). Due to a low recurrence rate and the presence of cloud cover, it was not always possible to obtain even a fragment of Landsat-7 or Landsat-8 data for the study area during the vegetation season [37]. Since full access was open to Sentinel-2 satellite data in late 2015, we had new additional possibilities for solving the tasks under discussion. Sentinel-2 data have a higher spatial resolution and greater recurrence rate compared with Landsat- 7 and Landsat-8 data, which considerably adds functionality to the status monitoring of restored peatlands.

\subsection{Methodology}

We analyzed data from all six spectral bands for Landsat-7, all four spectral bands for Spot-5, and all four spectral bands for Spot-6. For Landsat- 8 and Sentinel-2, we also used six spectral bands that coincided with Landsat-h for geographical reference (up to $100 \mathrm{~m}$ ), and to improve the binding quality, Spot- 6 data were used as the reference data.

We assumed that the use of Landsat-7 and Landsat- 8 RSD could provide a link between all other RSD as they include visible, NIR, and SWIR bands. On the basis of Landsat data, it is possible to draw analogies between different RSD, which in time did not have an intersection, but can be compared indirectly through the Landsat data.

An acceptable time for the fire hazard analysis of abandoned peatlands based on satellite data for the central part of European Russia is the vegetation season using the interval from mid-May to mid-September.

We used a previously developed classification system of land cover using Landsat- 5 and Landsat-7 RSD [33] that enabled us to solve problems related to fire hazard and rewetting efficacy in human-disturbed peatlands [21]. The classification system had already been used to address the problems in the Meschera NP, and for monitoring the fire hazard level for peatlands in the Moscow Province [22]. We confirmed the possibility of using the satellite data for the allocation within beforehand contoured peatland complexes and six land cover classes that met our objectives: (1) areas of bare and burned peat including patches with sparse vegetation cover ("bare peat": this and similar short names for other classes given in brackets will be used later in the text, tables, and captions); (2) willow herb, small reed, and small birch reed communities, formed during the overgrowth of bare and burned peat ("grass"); (3) communities with pine, differently depressed pine stands ("pine"); (4) communities dominated by willow and birch, mainly birch communities on overgrowing milled fields, occasionally with alder and aspen stands ("willow-birch"); (5) hydrophilic communities with cattail and reed, formed by hydrophilic species such as cattail and reed, water plantain, and different cotton grasses in wet areas ("hydrophilic"); and (6) water bodies including those formed after natural or artificial rewetting of the peatland areas ("water"). The first two classes are characterized by the lowest groundwater levels, a periodically dry soil surface, and the highest degree of fire hazard. The third and fourth classes of land cover occupy an intermediate position. The fifth is characterized by high groundwater levels close to or above the surface, and with the sixth class, they are practically a non-fire hazard. For more information on the classes, see Appendix A.

Results of an earlier study [33] showed that using supervised classification and the minimum distance method for Landsat-5 and Landsat-7 data satisfactorily solved the objective of assessing the state of fire hazardous peatlands and the effectiveness of their rewetting. In this study, we selected four training samples for class "bare peat" (with the area of 0.70, 1.08, 3.29, and 1.62 ha), one sample each for the classes "grass" (0.72 ha) and "pine" (2.46 ha), two samples for the class "willow-birch" (1.08 and $0.72 \mathrm{ha})$, three samples for the class "hydrophilic" $(0.82,0.90$, and $0.54 \mathrm{ha})$, and one sample for the class "water" (0.68 ha). Training samples were chosen based on accessibility. More samples for most mixing classes such as "bare peat", "willow-birch", and "hydrophilic" were added for a more accurate separation when working with Spot-6. According to the ground truth data, the samples were relatively homogeneous, so a training dataset could be formed to be used for supervised classification. 
The work presented was divided into three parts. In the first part, we applied the previously tested supervised classification minimum distance method [33] for datasets: Spot-5, Spot-6, and Landsat-7 from 2013. Additional analysis using the unsupervised classification was performed on the Spot-6 dataset. Generally, the unsupervised classification procedure helped to automatically separate images to a given number of classes; during analysis with the training samples, each class wasassociated with a land cover class from the six-class set.

In the second part, based on the earlier proven suitability of the Landsat-7 RSD [33] from 2013, its classification was carried out by different methods: object-oriented, trees, and neural networks. To cover the study area with satellite source data from Landsat-7, we used two scenes dated 1 July 2013 and 11 August 2013. The ETM+ system has offered scenes with gaps since 2003. First, the classification of each original image with omissions was carried out, and then the overall result was synthesized.

In the third part, based on the results of the first two parts, the analysis of object-oriented and minimum distance for Landsat- 8 and Sentinel-2 datasets from 2016 was carried out to confirm the conclusion about the close accuracy of classifications of these two methods.

An important aspect of this work is the accuracy assessment of land cover status and classification [38]. According to the planned work of the Meschera National Park, the current status of the vegetation cover is described each summer period based on field surveys. The descriptive details for different peatland complexes may vary, but its spatial accuracy is sufficient to verify the accuracy of the classifications (six land cover classes) applied in our study. To assess the quality of the classification results, a set of testing units waschosen by a systematic sampling method with a step of $100 \mathrm{~m}$ for 2013 and 2016 within the framework of the land-based survey areas. The area of each testing unit was $20 \times 20 \mathrm{~m}$. A total of 480 testing units were taken for 2013 for the first and second parts of comparisons and 419 for the third part of comparisons for 2016. Testing units evenly covered all the considered land cover classes. The quality of the classification results was assessed using complete error matrices and we calculated the classification accuracies of the classes' separation [39] as presented in Table 2.

\section{Results}

Figure 2 shows the mean quantization levels of the spectral radiance for identifying land cover classes obtained from multispectral satellite images and training samples, and provides an overview of class separation possibilities using different bands. NIR, SWIR 2, and SWIR 3 bands are better for class separation, as demonstrated by the Landsat-7 bands. Spot- 5 data, having NIR and SWIR 2 bands, are also acceptable for separating the focal classes (see Table 1). Both Landsat-7 (Landsat-8) and Spot-5 have a band containing a 1.55 (minimum for Landsat 7)-1.66 (max for Landsat-8) $\mu \mathrm{m}$ SWIR range. The Spot- 6 dataset lacks this band.

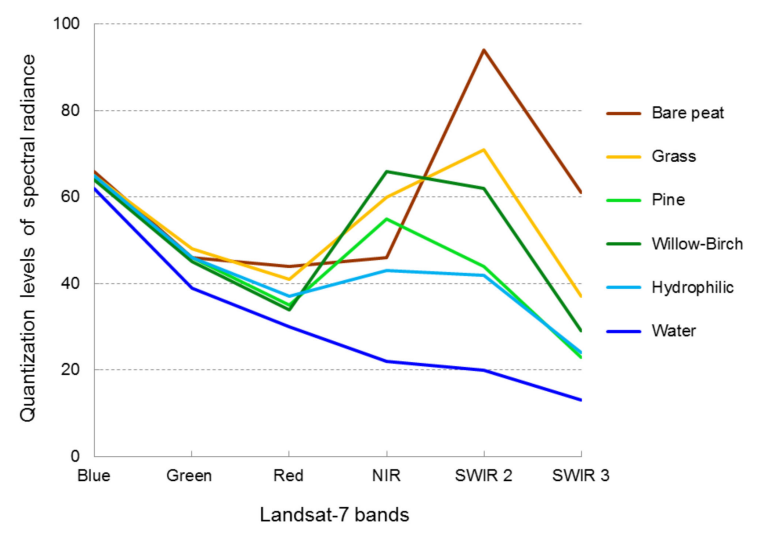

Figure 2. Spectral radiance bands for identifying land cover classes. 
Figure 3 presents the pixel distribution of the training set for various combinations of Landsat-7, Spot-5, and Spot-6 spectral bands. Figure 3a (Landsat-7) and Figure 3d (Spot-5) show a too-dense arrangement of pixels in the training data classes in the RED—near infrared (NIR) spectral bands. In Figure 3b,c (Landsat-7) and Figure 3e (Spot-5), these pixels are arranged more loosely, which more accurately separates the classes. Figure $3 f$ (Spot-6) shows that the training data created some separation difficulties. However, this approach did not solve the problem of separating the "bare peat" and "hydrophilic" communities in the border zone, probably due to the high moisture content of the peat. The lack of the SWIR band in the Spot-6 data was also noticeable.

The Landsat-7 (Landsat-8) and Spot-5 satellites have NIR bands from 0.75 to $0.90 \mu \mathrm{m}$ and SWIR bands from 1.58 to $1.75 \mu \mathrm{m}$. The SWIR band shows itself to be decisive for the separation of the classes we need (Table 2). Spot- 6 has four bands with wavelengths between 0.45 and $0.89 \mu \mathrm{m}$ without the SWIR band (Table 1) and, as expected, the classification with Spot-6 data showed a low accuracy (Table 2). Supervised classification of Spot-6 RSD was unsatisfactory, and we decided to complete the classification without training the 30-class ISODATA unsupervised classification. In this particular case, we were guided by the following considerations. To conduct supervised classification, we selected areas on the images in accordance with the ground truth reference small units: training samples with related spectral characteristics for each class. At this stage of supervised classification in the training samples, one class could likely be confused with areas of another class, which further worsened the classification results.

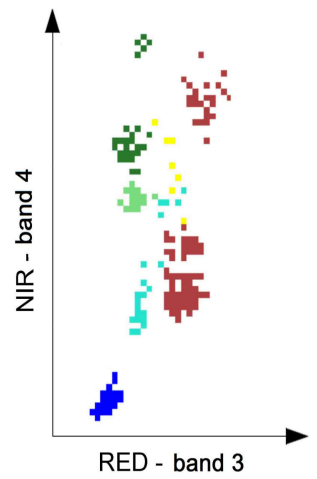

(a)

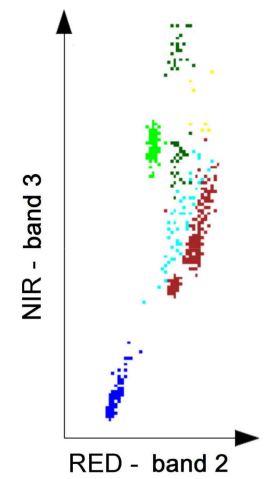

(d)

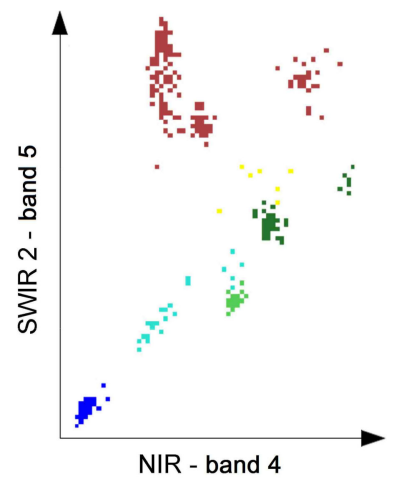

(b)

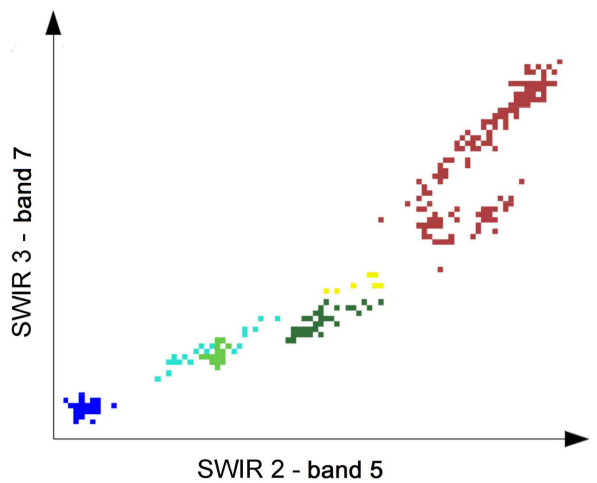

(c)

(1) Landsat-7

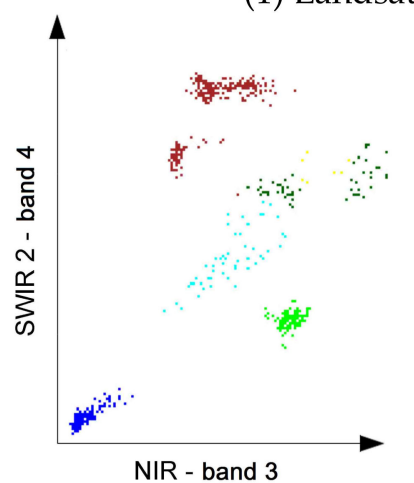

(e)

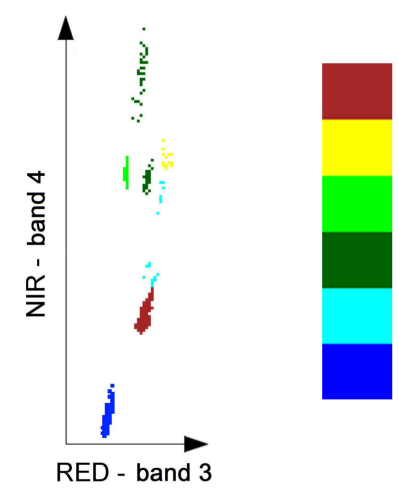

(f)

(2) Spot-5

(3) Spot-6

Figure 3. Classes of training data areas in two-dimensional space of spectral radiance values for various combinations of data bands: (a) RED-NIR for Landsat-7; (b) NIR-SWIR 2 for Landsat-7; (c) SWIR 2-SWIR 3 for Landsat-7; (d) RED-NIR for Spot-5; (e) NIR-SWIR 2 for Spot-5; (f) RED-NIR for Spot-6. 
Table 2. Complete error matrices and calculated classification accuracies of class separation.

\begin{tabular}{|c|c|c|c|c|c|c|c|c|}
\hline \multicolumn{9}{|c|}{ Spot-5 } \\
\hline Classes & \multicolumn{8}{|c|}{ Actual } \\
\hline Calculated & Bare Peat & Grass & Pine & Willow-Birch & Hydrophilic & Water & $\Sigma$ & Us. Accuracy ${ }^{1}(\%)$ \\
\hline Bare peat & 108 & 1 & 0 & 0 & 0 & 0 & 109 & 99.1 \\
\hline Grass & 2 & 70 & 1 & 4 & 1 & 0 & 78 & 89.7 \\
\hline Pine & 0 & 0 & 33 & 0 & 1 & 0 & 34 & 97.1 \\
\hline Willow-Birch & 2 & 4 & 0 & 76 & 1 & 0 & 83 & 91.6 \\
\hline Hydrophilic & 2 & 0 & 1 & 0 & 87 & 3 & 93 & 93.5 \\
\hline Water & 0 & 0 & 0 & 0 & 1 & 82 & 83 & 98.8 \\
\hline$\Sigma$ & 114 & 75 & 35 & 80 & 91 & 85 & 480 & \\
\hline Pr. Accuracy ${ }^{2}(\%)$ & 94.7 & 93.3 & 94.3 & 95.0 & 95.6 & 96.5 & & $95.00^{3}$ \\
\hline \multicolumn{9}{|c|}{ Landsat-7 } \\
\hline Bare peat & 110 & 2 & 0 & 0 & 0 & 0 & 112 & 98.2 \\
\hline Grass & 3 & 72 & 0 & 4 & 1 & 0 & 80 & 90.0 \\
\hline Pine & 0 & 0 & 32 & 1 & 1 & 0 & 34 & 94.1 \\
\hline Willow-Birch & 1 & 1 & 2 & 75 & 0 & 0 & 79 & 94.9 \\
\hline Hydrophilic & 0 & 0 & 1 & 0 & 87 & 5 & 93 & 93.5 \\
\hline Water & 0 & 0 & 0 & 0 & 2 & 80 & 82 & 97.6 \\
\hline$\Sigma$ & 114 & 75 & 35 & 80 & 91 & 85 & 480 & \\
\hline Pr. Accuracy ${ }^{2}(\%)$ & 96.5 & 96.0 & 91.4 & 93.8 & 95.6 & 94.1 & & $95.00^{3}$ \\
\hline \multicolumn{9}{|c|}{ Spot-6 data (supervised classification) } \\
\hline Bare peat & 53 & 0 & 0 & 0 & 15 & 0 & 68 & 77.9 \\
\hline Grass & 0 & 51 & 5 & 2 & 1 & 0 & 59 & 86.4 \\
\hline Pine & 0 & 1 & 24 & 2 & 1 & 0 & 28 & 85.7 \\
\hline Willow-Birch & 10 & 21 & 6 & 74 & 6 & 0 & 117 & 63.2 \\
\hline Hydrophilic & 51 & 2 & 0 & 2 & 67 & 4 & 126 & 53.2 \\
\hline Water & 0 & 0 & 0 & 0 & 1 & 81 & 82 & 98.8 \\
\hline$\Sigma$ & 114 & 75 & 35 & 80 & 91 & 85 & 480 & \\
\hline Pr. Accuracy ${ }^{2}(\%)$ & 46.5 & 68.0 & 68.6 & 92.5 & 73.6 & 95.3 & & $72.92^{3}$ \\
\hline \multicolumn{9}{|c|}{ Spot-6 data (unsupervised classification) } \\
\hline Bare peat & 94 & 2 & 0 & 0 & 38 & 0 & 134 & 70.1 \\
\hline Grass & 1 & 61 & 3 & 2 & 2 & 0 & 69 & 88.4 \\
\hline Pine & 0 & 0 & 27 & 2 & 0 & 0 & 29 & 93.1 \\
\hline Willow-Birch & 2 & 9 & 5 & 75 & 1 & 0 & 92 & 81.5 \\
\hline Hydrophilic & 17 & 3 & 0 & 1 & 49 & 6 & 76 & 64.5 \\
\hline Water & 0 & 0 & 0 & 0 & 1 & 79 & 80 & 98.8 \\
\hline$\Sigma$ & 114 & 75 & 35 & 80 & 91 & 85 & 480 & \\
\hline Pr. Accuracy ${ }^{2}(\%)$ & 82.5 & 81.3 & 77.1 & 93.8 & 53.8 & 92.9 & & $80.21^{3}$ \\
\hline
\end{tabular}

Note: ${ }^{1}$ Producer's accuracy, ${ }^{2}$ User's accuracy, ${ }^{3}$ Overall classification accuracy.

Unsupervised classification of the Spot- 6 data helped increase the identification quality for the following land cover classes: "bare peat" by 36\%, "grass" by 13\%, "pine" by $9 \%$, and "willow-birch" by $1 \%$. Simultaneously, the identification quality of the "hydrophilic" class decreased by $20 \%$ and "water" by $2 \%$ (Table 2). Examples of the classification results for different satellite images on one, rather a representative, test site are displayed in Figure 4.

The comparison shows similar classification results for the data from Landsat-7 (Figure 4a) and Spot-5 (Figure 4b), even when considering the higher resolution of Spot-5 (10 m, Landsat-7 $30 \mathrm{~m}$ ) data and different imaging time (the Spot- 5 images dated 13 September 2013 were obtained during a rainier period than those from Landsat-7 that were captured a month earlier).

Locations of classes in Figure 4c (Spot-6, supervised classification) considerably differed from the previous two graphs. Notably, classes 1 and 5 could hardly be identified due to the characteristics of the original satellite data. Based on Spot-6 data, it is not possible to classify classes "peat" and "hydrophilic" correctly. There is no SWIR band in this dataset, which obviously makes it impossible to separate these classes, whose characteristics are fundamentally different from the point of view of the tasks to be solved correctly. Separation of these two classes was improved using unsupervised classification (Figure $4 \mathrm{~d}$ ); the locations of the two offending classes looked similar to those in Figure $4 \mathrm{~b}$ (Spot-5). 
However, the error matrices (Table 2) showed that Spot-6 data classification was not sufficiently accurate for the identification of classes of observable land cover.

To assess the possibility of using another software package, the ScanEx Image Processor, we tested supervised classification using three methods: object-oriented, trees, and neural networks [40], using Landsat-7 ETM+ data from 2013. The accuracy of the land cover class identification using the above data classifications was assessed through the complete error matrices (Table 3).
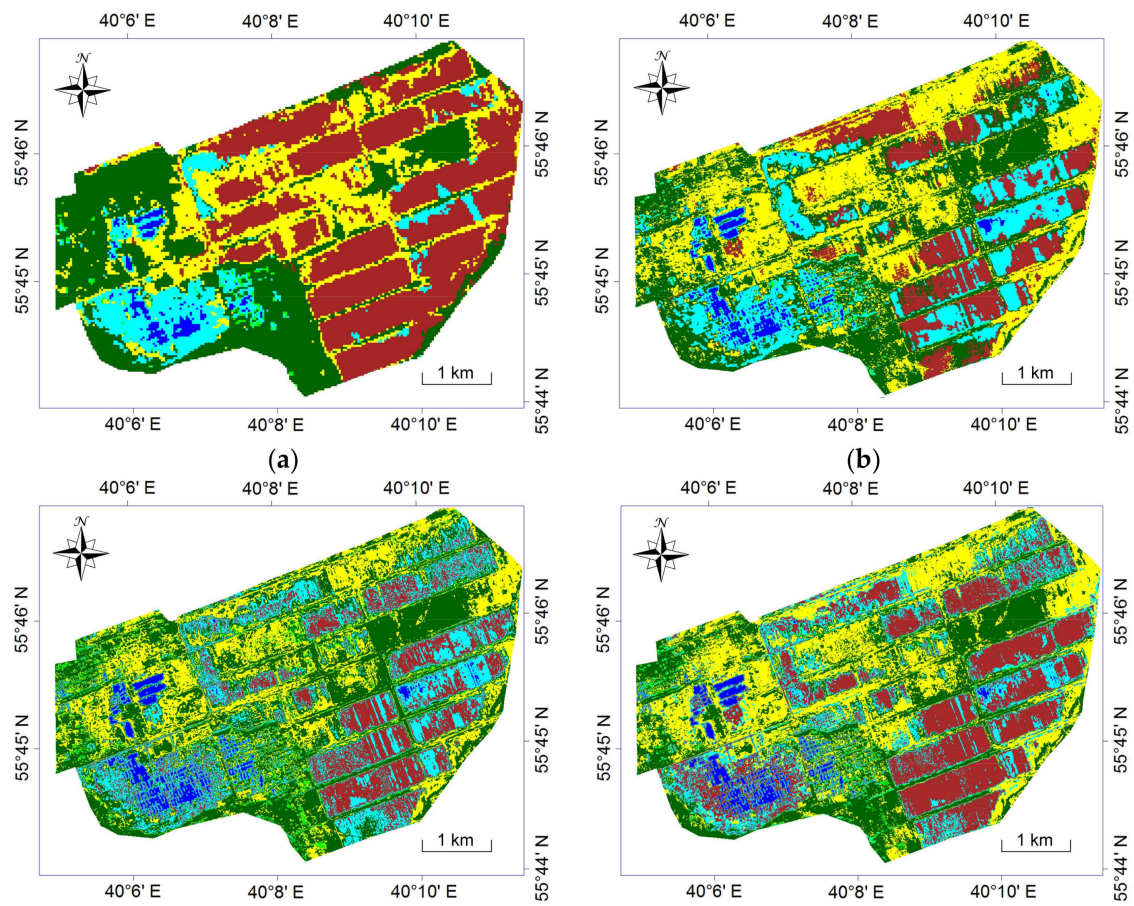

(c)

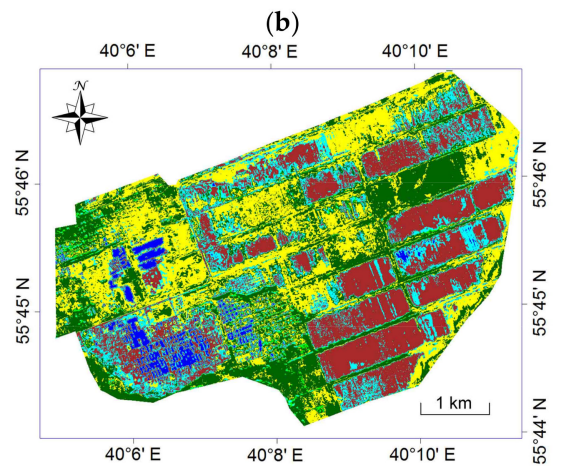

(d)
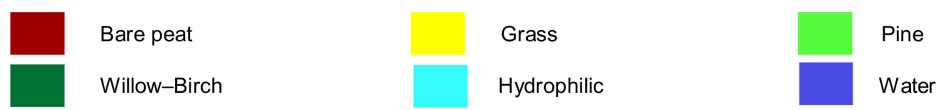

Figure 4. Minimum distance classification examples of different satellite images for a peat extraction site in the Orlovskoe peatland complex: (a) Landsat-7; (b) Spot-5; (c) Spot-6 (supervised classification); and (d) Spot-6 (unsupervised classification).

Table 3 shows the complete error matrix obtained in an earlier analysis using the minimum distance method (Table 2). The classifications are fairly closely grouped, having an overall good classification accuracy with the first two methods: the minimum distance method was $95.00 \%$ accurate and the object-oriented method was $94.58 \%$. Classification accuracies obtained by the neural network and trees methods, at $88.96 \%$ and $80.83 \%$, respectively, are insufficient methods for the status monitoring of abandoned peat extraction sites given the required level of detail.

The object-oriented method with interactive classification using the ScanEx Image Processor (SIP) package offers a potentially good transition from the minimum distance method of the Erdas Imagine (EI) package. Figure 5 presents the results of various classifications of the Landsat-7 ETM+ data obtained for the Ostrovskoye peatland complex using the ScanEx Image Processor software package and, for comparison, the data obtained by the minimum distance method using the Erdas Imagine software package. 
Table 3. Complete error matrices and calculated classification accuracies of Landsat-7 using ScanEx Image Processor (SIP) and Erdas Imagine (EI) methods.

\begin{tabular}{|c|c|c|c|c|c|c|c|c|}
\hline \multicolumn{9}{|c|}{ Minimum Distance } \\
\hline Classes & & & & & Actual & & & \\
\hline Calculated & Bare Peat & Grass & Pine & Willow-Birch & Hydrophilic & Water & $\Sigma$ & Us. Accuracy ${ }^{1}(\%)$ \\
\hline Bare peat & 110 & 2 & 0 & 0 & 0 & 0 & 112 & 98.2 \\
\hline Grass & 3 & 72 & 0 & 4 & 1 & 0 & 80 & 90.0 \\
\hline Pine & 0 & 0 & 32 & 1 & 1 & 0 & 34 & 94.1 \\
\hline Willow-Birch & 1 & 1 & 2 & 75 & 0 & 0 & 79 & 94.9 \\
\hline Hydrophilic & 0 & 0 & 1 & 0 & 87 & 5 & 93 & 93.5 \\
\hline Water & 0 & 0 & 0 & 0 & 2 & 80 & 82 & 97.6 \\
\hline$\Sigma$ & 114 & 75 & 35 & 80 & 91 & 85 & 480 & \\
\hline Pr. Accuracy ${ }^{2}(\%)$ & 96.5 & 96.0 & 91.4 & 93.8 & 95.6 & 94.1 & & $95.00^{3}$ \\
\hline \multicolumn{9}{|c|}{ Object-oriented } \\
\hline Bare peat & 110 & 1 & 0 & 0 & 0 & 0 & 111 & 99.1 \\
\hline Grass & 2 & 70 & 1 & 5 & 0 & 0 & 78 & 89.7 \\
\hline Pine & 0 & 0 & 30 & 0 & 3 & 0 & 33 & 90.9 \\
\hline Willow-Birch & 2 & 4 & 3 & 75 & 0 & 0 & 84 & 89.3 \\
\hline Hydrophilic & 0 & 0 & 1 & 0 & 88 & 4 & 93 & 94.6 \\
\hline Water & 0 & 0 & 0 & 0 & 0 & 81 & 81 & 100.0 \\
\hline$\Sigma$ & 114 & 75 & 35 & 80 & 91 & 85 & 480 & \\
\hline Pr. Accuracy ${ }^{2}(\%)$ & 96.5 & 93.3 & 85.7 & 93.8 & 96.7 & 95.3 & & $94.58^{3}$ \\
\hline \multicolumn{9}{|c|}{ Neural networks } \\
\hline Bare peat & 110 & 6 & 0 & 4 & 0 & 0 & 120 & 91.7 \\
\hline Grass & 3 & 61 & 0 & 3 & 0 & 0 & 67 & 91.0 \\
\hline Pine & 0 & 0 & 25 & 0 & 6 & 0 & 31 & 80.6 \\
\hline Willow-Birch & 1 & 8 & 9 & 73 & 5 & 0 & 96 & 76.0 \\
\hline Hydrophilic & 0 & 0 & 1 & 0 & 79 & 6 & 86 & 91.9 \\
\hline Water & 0 & 0 & 0 & 0 & 1 & 79 & 80 & 98.8 \\
\hline$\Sigma$ & 114 & 75 & 35 & 80 & 91 & 85 & 480 & \\
\hline Pr. Accuracy ${ }^{2}(\%)$ & 96.5 & 81.3 & 71.4 & 91.3 & 86.8 & 92.9 & & $88.96^{3}$ \\
\hline \multicolumn{9}{|c|}{ Trees } \\
\hline Bare peat & 105 & 13 & 0 & 15 & 0 & 0 & 133 & 78.9 \\
\hline Grass & 6 & 45 & 1 & 8 & 0 & 0 & 60 & 75.0 \\
\hline Pine & 0 & 0 & 22 & 0 & 5 & 0 & 27 & 81.5 \\
\hline Willow-Birch & 1 & 6 & 10 & 57 & 5 & 0 & 79 & 72.2 \\
\hline Hydrophilic & 2 & 11 & 2 & 0 & 79 & 5 & 99 & 79.8 \\
\hline Water & 0 & 0 & 0 & 0 & 2 & 80 & 82 & 97.6 \\
\hline$\Sigma$ & 114 & 75 & 35 & 80 & 91 & 85 & 480 & \\
\hline Pr. Accuracy ${ }^{2}(\%)$ & 92.1 & 60.0 & 62.9 & 71.3 & 86.8 & 94.1 & & $80.83^{3}$ \\
\hline
\end{tabular}

Note: ${ }^{1}$ Producer's accuracy, ${ }^{2}$ User's accuracy, ${ }^{3}$ Overall classification accuracy.

The identification accuracy of land cover classes for 2016 was assessed through two classification methods using the Landsat- 8 and Sentinel-2 datasets: object-oriented (SIP) and minimum distance (EI). The error matrix (Table 4) shows a relatively high and similar overall classification accuracy of the four classification results. 


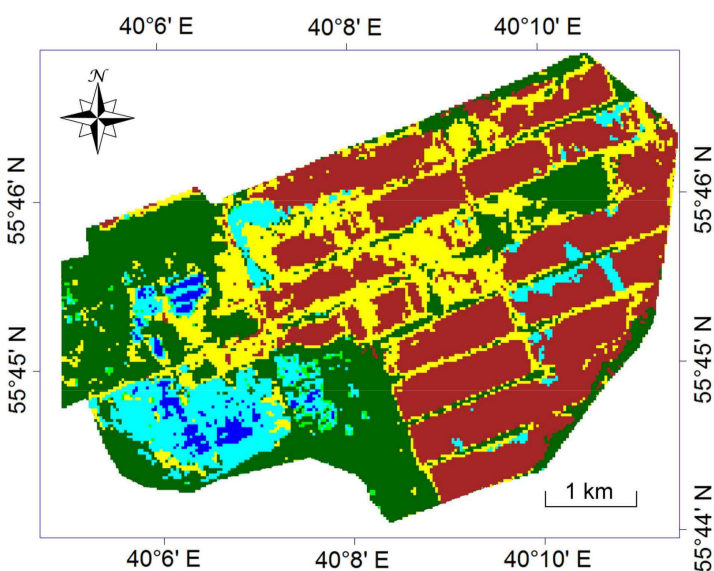

(a)

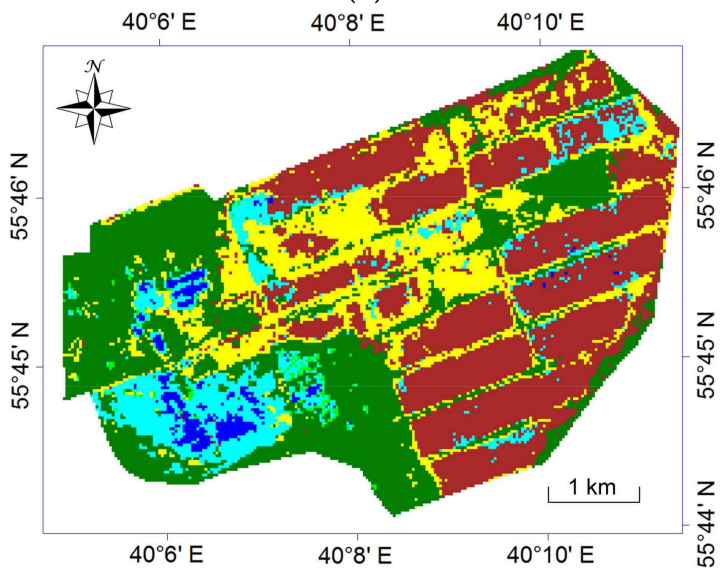

(c)

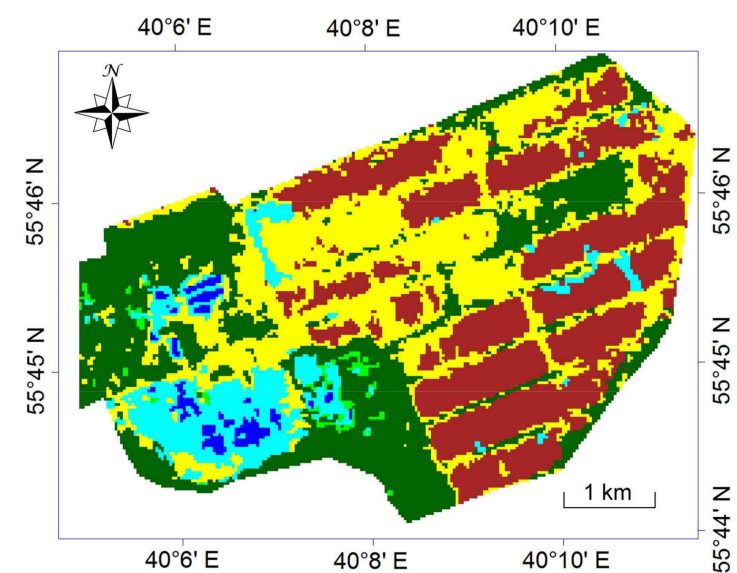

(b)

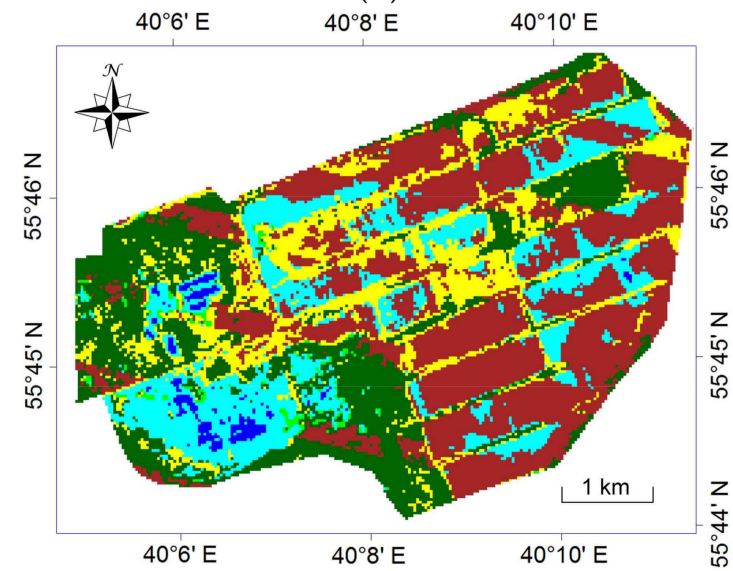

(d)

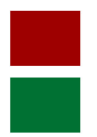

Bare peat
Willow-Birch

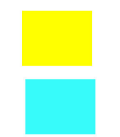

Grass

Hydrophilic

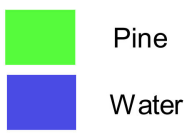

Figure 5. Landsat-7 ETM+ classification examples using different methods for a peat extraction site in the Orlovskoe peatland complex: (a) Erdas Imagine (EI) Minimum Distance; (b) ScanEx Image Processor (SIP) Object-oriented; (c) SIP Neural networks; and (d) SIP Trees.

The greatest accuracy was obtained from the Sentinel-2 data using the minimum distance method $(97.14 \%)$, followed by the Sentinel-2 data using the object-oriented method $(95.47 \%)$, and then the Landsat- 8 data using the minimum distance method $(95.23 \%)$, and the lowest accuracy was obtained with the Landsat-8 data using the object-oriented method (94.03\%). The results confirm the classification accuracy of the Sentinel-2 data that have a higher spatial resolution $(10-20 \mathrm{~m})$ compared with the Landsat-7 data $(30 \mathrm{~m})$. The results also confirm the above hypothesis about the possibility of an adequate transition from the minimum distance method of the EI package to the object-oriented method of the SIP package for data analysis in our task.

Figure 6 shows the classification results of the Landsat- 8 and Sentinel-2 datasets using two classification methods for the Orlovskoye peatland complex: the object-oriented SIP and the minimum distance EI. Figure 6a shows the minimum distance Sentinel-2 data, and Figure $6 \mathrm{c}$ shows the object-oriented Sentinel-2 data that have a higher spatial resolution. As mentioned in Section 2.2 for the Landsat- 8 and Sentinel-2 RSD, we only used bands that coincided with Landsat-7 to ensure comparability of all RSD being reviewed. In addition, we tested the effect of the use of Sentinel-2 Vegetation Red Edge bands and less bare peat and more vegetation was defined, which correlated well with other studies [41]. 
Table 4. Complete error matrices and calculated classification accuracies of Landsat- 8 and Sentinel-2 using different methods.

\begin{tabular}{|c|c|c|c|c|c|c|c|c|}
\hline \multicolumn{9}{|c|}{ Sentinel-2 Minimum Distance } \\
\hline Classes & & & & & Actual & & & \\
\hline Calculated & Bare Peat & Grass & Pine & Willow-Birch & Hydrophilic & Water & $\Sigma$ & Us. Accuracy ${ }^{1}(\%)$ \\
\hline Bare peat & 93 & 1 & 0 & 0 & 3 & 0 & 97 & 95.9 \\
\hline Grass & 1 & 99 & 0 & 1 & 0 & 0 & 101 & 98.0 \\
\hline Pine & 0 & 0 & 18 & 0 & 0 & 0 & 18 & 100.0 \\
\hline Willow-Birch & 0 & 1 & 2 & 90 & 0 & 0 & 93 & 96.8 \\
\hline Hydrophilic & 0 & 0 & 0 & 0 & 59 & 1 & 60 & 98.3 \\
\hline Water & 0 & 0 & 0 & 0 & 2 & 48 & 50 & 96.0 \\
\hline$\Sigma$ & 94 & 101 & 20 & 91 & 64 & 49 & 419 & \\
\hline Pr. Accuracy 2 (\%) & 98.9 & 98.0 & 90.0 & 98.9 & 92.2 & 98.0 & & $97.14^{3}$ \\
\hline \multicolumn{9}{|c|}{ Landsat- 8 Minimum Distance } \\
\hline Bare peat & 93 & 2 & 0 & 0 & 0 & 0 & 95 & 97.9 \\
\hline Grass & 0 & 97 & 0 & 3 & 0 & 0 & 100 & 97.0 \\
\hline Pine & 0 & 0 & 17 & 1 & 4 & 0 & 22 & 77.3 \\
\hline Willow-Birch & 0 & 1 & 2 & 87 & 0 & 1 & 91 & 95.6 \\
\hline Hydrophilic & 1 & 0 & 1 & 0 & 57 & 1 & 60 & 95.0 \\
\hline Water & 0 & 0 & 0 & 0 & 3 & 48 & 51 & 94.1 \\
\hline$\Sigma$ & 94 & 100 & 20 & 91 & 64 & 50 & 419 & \\
\hline Pr. Accuracy ${ }^{2}(\%)$ & 98.9 & 97.0 & 85.0 & 95.6 & 89.1 & 96.0 & & $95.23^{3}$ \\
\hline \multicolumn{9}{|c|}{ Sentinel-2 Object-oriented } \\
\hline Bare peat & 92 & 4 & 0 & 0 & 2 & 0 & 98 & 93.9 \\
\hline Grass & 2 & 95 & 0 & 1 & 1 & 0 & 99 & 96.0 \\
\hline Pine & 0 & 0 & 16 & 0 & 0 & 0 & 16 & 100.0 \\
\hline Willow-Birch & 0 & 0 & 4 & 89 & 0 & 0 & 93 & 95.7 \\
\hline Hydrophilic & 0 & 1 & 0 & 1 & 59 & 1 & 62 & 95.2 \\
\hline Water & 0 & 0 & 0 & 0 & 2 & 49 & 51 & 96.1 \\
\hline$\Sigma$ & 94 & 100 & 20 & 91 & 64 & 50 & 419 & \\
\hline Pr. Accuracy ${ }^{2}(\%)$ & 97.9 & 95.0 & 80.0 & 97.8 & 92.2 & 98.0 & & $95.47^{3}$ \\
\hline \multicolumn{9}{|c|}{ Landsat- 8 Object-oriented } \\
\hline Bare peat & 92 & 7 & 0 & 0 & 0 & 0 & 99 & 92.9 \\
\hline Grass & 2 & 92 & 0 & 2 & 1 & 1 & 98 & 93.9 \\
\hline Pine & 0 & 0 & 17 & 0 & 0 & 0 & 17 & 100.0 \\
\hline Willow-Birch & 0 & 0 & 3 & 88 & 2 & 0 & 93 & 94.6 \\
\hline Hydrophilic & 0 & 1 & 0 & 1 & 57 & 1 & 60 & 95.0 \\
\hline Water & 0 & 0 & 0 & 0 & 4 & 48 & 52 & 92.3 \\
\hline$\Sigma$ & 94 & 100 & 20 & 91 & 64 & 50 & 419 & \\
\hline Pr. Accuracy ${ }^{2}(\%)$ & 97.9 & 92.0 & 85.0 & 96.7 & 89.1 & 96.0 & & $94.03^{3}$ \\
\hline
\end{tabular}

Having analyzed the possibilities of multispectral satellite scanners, we concluded that Spot-6 data were insufficient for the status monitoring of abandoned peat extraction sites given the required accuracy due to the lack of an SWIR band [42]. The main problem of data lacking the SWIR band is that the data tend to confuse patches of bare peat and hydrophilic vegetation, which are classes with completely different meanings in the monitoring context [42].

Classifications based on Spot-5 [33], Landsat-7, Landsat-8, and Sentinel-2 RSD showed close high accuracy levels. Therefore, these types of data can be combined for the analysis of large territories, providing a generally high level of accuracy of the final results.

Another aspect analyzed was the spatial resolution of the satellite data compared. Our focal sites-drained and cutover peatlands-show considerable spatial fragmentation. For example, peat milling fields (peat milling having been the most common industrial peat extraction method since the 1950s) have a drainage network of so-called open ditches that divide milling fields; distances between them are about $40 \mathrm{~m}$. Agricultural lands established on partially cutover peat extraction sites as a revegetation measure usually have similar drainage networks. Open ditches are complemented by catching and main ditches, and other elements of drainage networks. Drainage networks may be in varying conditions. More often than not, they are overgrown with hydrophilic vegetation and have 
patches of open water surface. Fragmentation affects the general spectral characteristics of such objects. Therefore, it is reasonable to have satellite data with a spectral resolution higher than $30 \mathrm{~m}$ [42]. In our study, the RSD used has the following spatial resolution: Spot-6 6 m, Spot-5 10 m, Sentinel-2 10-20 m, and Landsat-7 and Landsat-8 $30 \mathrm{~m}$.

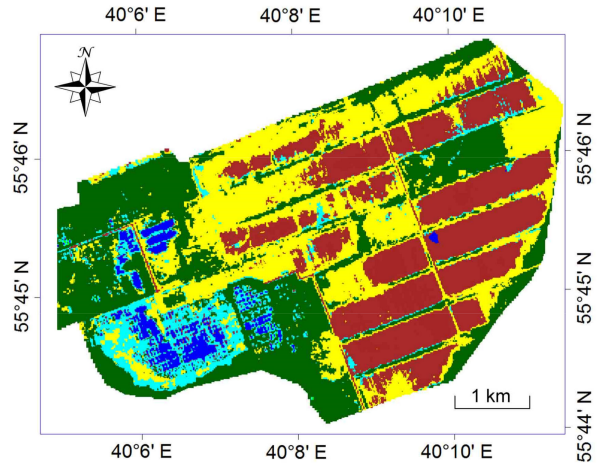

(a)

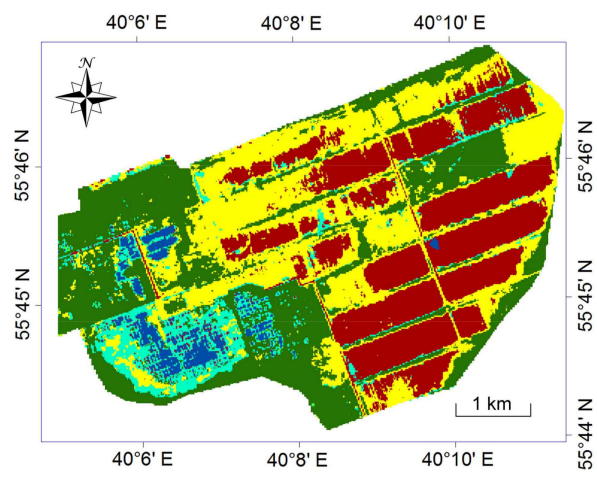

(c)

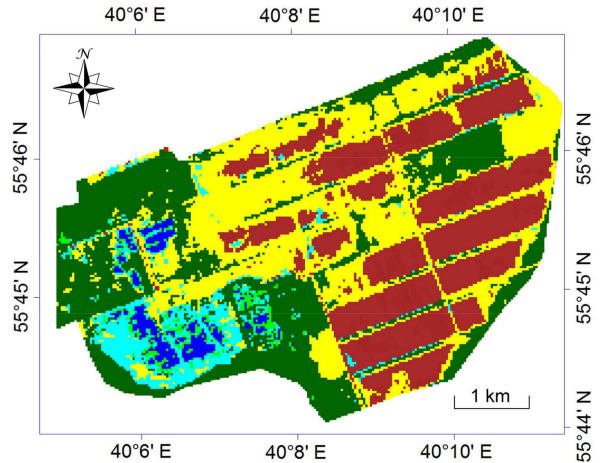

(b)

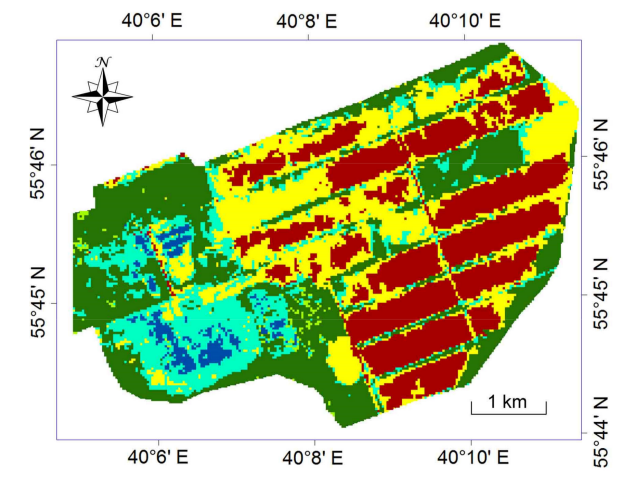

(d)

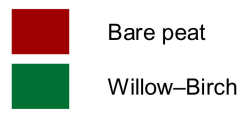

Grass

Hydrophilic

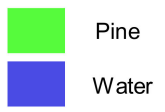

Figure 6. Classification examples of satellite images for the peat extraction site in the Orlovskoe peatland complex: (a) EI Minimum Distance Sentinel-2; (b) EI Minimum Distance Landsat-8; (c) SIP Object-oriented Sentinel-2; (d) SIP Object-oriented Landsat-8.

The Spot-6 data have the most convenient spatial resolution to solve the above-mentioned problems. Their images are the most detailed of the whole set analyzed $(6 \mathrm{~m})$. The Spot- 5 data with a spatial resolution of $10 \mathrm{~m}$ also provide a sufficient accuracy for solving the problems. However, the Landsat-7 data are too rough $(30 \mathrm{~m})$ and, as one can see from Figure 4, using these data results in a decrease of identification accuracy. At the same time, ground-truthing of classification quality has shown that spectral resolution is more important than spatial resolution for solving our problems.

\section{Discussion}

Rewetting of abandoned peatlands and mire restoration, which is statutorily required in Russia, is the most effective means aimed to prevent adverse processes and reduce fire hazard on the lands where revegetation for economic purposes is impractical [20]. However, given the scope of the problem, prioritization of to-be-rewetted sites should be made and follow-up monitoring carried out in order to assess the effectiveness of these activities. It should be noted that the abandoned peatlands are expansive, rough terrains, and this impedes surface mapping. Vegetation cover is 
highly patterned. It has a variety of trends, particularly due to fluctuations in weather conditions and occasional disturbances by peat fires. Therefore, satellite data provide the most promising and practical framework for a monitoring system, including, among other things, abandoned peat extraction sites [43]. The use of regular satellite images facilitates the monitoring of peatland status as well as the planning, control, and effectiveness assessment of rewetting activities [44,45].

Assessment of the area of abandoned peatlands in terms of their fire hazard is necessary: first, to identify the most fire hazardous sites including those which need rewetting; and second, to assess the effectiveness of the measures applied. The effect of rewetting in relation to mire restoration does not occur immediately, and could take years. This requires the long-term monitoring of such objects, which cannot be provided by data from only one satellite. Some stop working, and new ones appear. In addition, the use of several satellites provides the best temporary and area coverage of the territory.

The first version of this approach based on Landsat- 5 and Landsat-7 RSD has already been tested on peatland complexes in the "Meschera" National Park, Vladimir Province [33]. Classification, which included six land cover classes to enable the assessment of the fire hazard status of human-disturbed peatlands, was developed [21]. This classification hasalready been tested and applied for the "Meschera" NP and fire hazardous peatlands in the Moscow Province to assess their status, prioritize for rewetting, and to check the results [22].

However, the extensive fires that took place in the center of European Russia in 2010 [22] called for the further development of methodological approaches that use remote sensing data to assess the status of fire hazardous peatlands and rewetting effectiveness [25]. Continuous monitoring of peatlands throughout the fire danger season (spring to autumn) requires coverage by more thanone satellite RSD. However, experience prior to Sentinel-2 has shown that operative satellite data from high-resolution satellites are very fragmentary in time and space coverage, even for a frequently covered region like Moscow Province (total area 44,379 km², distance W-E: $320 \mathrm{~km}, \mathrm{~N}-\mathrm{S}: 305 \mathrm{~km}$, cf. The Netherlands, $41,526 \mathrm{~km}^{2}$ ) and even ordering commercial images taken at given intervals and for selected priority sites does not ensure success, should only one satellite system be used [46]. Therefore, the simultaneous use of two or three satellite systems that complement each other becomes actionable and practical to those also shown, for example, for Irish peatlands and heath [47], where active weather systems also present significant cloud cover for most of the year.

The analysis of the results helped to develop the general requirements for RSD (spatial resolution, combination of bands) and the pros and cons of using Spot-5, Spot-6, Landsat-7(8), and Sentinel-2. Having analyzed the possibilities of using multispectral satellite RSD, we proved that the Spot- 6 data had insufficient potential to monitor the status of abandoned peat extraction sites with the required accuracy because of the lack of the SWIR band. These and similar spectral data tended to confuse patches of bare peat with hydrophilic vegetation that had a diametrically opposed meaning in the context of monitoring objectives.

Landsat-7 and Landsat- 8 data enable the continuous monitoring of abandoned peat extraction sites, including both peatland complexes and more expansive areas. However, gaps in images caused by the Scan Line Corrector (SLC) instrument failure introduce considerable bounds to the use of Landsat-7. Now, these limitations can be compensated for by greater functionality of the Landsat-8 data with two additional spectral bands. One of them, Band 9, allows for the identification of even the slightest cloud cover. While Landsat- 8 opens modern and promising prospects, Landsat- 5 helps to carry out retrospective analyses based on using uniform data [42].

Landsat- 5 and Landsat- 7 have similar sets of spectral bands, with small differences in some band ranges. Considering the fact that peat milling fields have a drainage network of open ditches $40 \mathrm{~m}$ apart that divide milling fields, having satellite data with a more detailed spectral resolution than $30 \mathrm{~m}$ is desirable.

The data of Spot satellites have an image frequency of one scene per 26 days (Spot-5) or one scene daily (Spot-6 grouped with Spot-7). Moreover, we concluded that differences in land cover can be 
identified from Spot-5 data as precisely as from Landsat-7 data, which is sufficient for our purposes. Unfortunately, on 29 March 2015, the satellite was terminated. However, the Spot-5 data can still be used for retrospective analysis of our study objectives. Due to an insufficient image time and the presence of cloud cover in the Landsat- 7 and Landsat- 8 data, we could not always obtain even one data fragment for an analyzed object from each satellite over the vegetation season.

Full access to the satellite imagery of Sentinel-2 satellites at the end of 2015 provided new opportunities for the task under discussion. Vegetation Red Edge bands Sentinel-2, also called the red barrier of photosynthesis, where there is a sharp increase in the reflectance of green vegetation in the near-infrared radiation, can be used to estimate chlorophyll content [41]. Due to the phenomenon of the red barrier of the ground, the plants appear bright when imaging in the near-infrared range.

Generally, Sentinel-2 RSD, combined with the higher spatial resolution and smaller revisit period of Landsat-7 and Landsat-8, provides better opportunities for monitoring the status of abandoned, rewetted, and restoring peatlands.

Among the currently available analyzed satellite RSD, the following was determined. Spot- 6 (and Spot-7) was unsuitable for our task, having no SWIR band, with a small stripe covering $60 \mathrm{~km}$, but with a high spatial resolution of $6 \mathrm{~m}$, and an almost daily revisit time. Landsat-7 and Landsat- 8 had an infrequent revisit time of about twice per month, had an inadequate but acceptable spatial resolution of $30 \mathrm{~m}$, good swath width of $185 \mathrm{~km}$, and a full set of required spectral bands. Sentinel-2, with a spatial resolution in the required bands of up to $20 \mathrm{~m}$, a swath width of $290 \mathrm{~km}$, a revisit time of three to five days, and a full range of required bands, is currently the best open access option for land cover classification.

The results of this study demonstrate the possibility of the long-term analysis of the fire hazard of abandoned peatlands and the results of rewetting and restoration based on freely available Landsat, Sentinel, and commercial Spot RSD. For Landsat-8 and Sentinel-2 RSD, we only used bands that coincided with Landsat-7, and only from bands comparable to Landsat-7 to ensure comparability of all RSD under discussion. Landsat-7, Landsat-8, and Sentinel-2 RSD allowed the analysis of the current situation, and their forerunners, Landsat- 5 and Spot-5 RSD, provided a retrospective analysis. This responded to our objective of sustainably monitoring abandoned fire hazardous peatlands, especially for the long-term restoration succession of peatlands after rewetting.

\section{Conclusions}

Since the 1990s, extensive areas of peatlands that were drained for peat extraction and agriculture in European Russia are now, to a large extent, abandoned. Rewetting could return them to a waterlogged state, reducing their susceptibility to fires and peat oxidation. Degraded peatlands often cover large areas of hundreds to thousands of hectares, are scattered in space, have limited site access, are characterized by multispeed land cover dynamics, and require long-term monitoring. Groups of peatland complexes on a regional scale are rarely covered by one type of remote sensing data (RSD) source and require combining data from different scanners. Furthermore, the monitoring of long-term restoration dynamics of rewetted peatlands requires the continuity of RSD given the stopping and starting of operating satellites.

General RSD requirements such as spatial resolution and combination of bands were defined and the pros and cons of using Spot-5, Spot-6, Landsat-7, Landsat-8, and Sentinel-2 were tested for defining six previously developed land and vegetation classes [33] to assess the fire hazard status of abandoned peatlands for their prioritization for rewetting and monitoring of restoration results.

Landsat-7, Spot-5, and Spot-6 RSD from the same summer time period in 2013, and Landsat-8 and Sentinel-2 for 2016, were used to test different scanners for the approximately 120,000 ha of Meschera National Park, which has one of the largest concentrations of abandoned peatlands in Central Russia and the longest experience in large scale rewetting, dating back to the early 2000s. The results obtained could help to combine different RSD for assessing the state of specified objects, and to ensure the continuity of long-term monitoring. 
The main problems with the tested RSD are either related to the absence of the SWIR band, as with Spot-6 and Spot-7, or an insufficient spatial resolution as with Landsat, when one pixel simultaneously includes the drainage channel with open water and drainage spacing that creates a fire hazard such as with bare peat. Lack of an SWIR band makes the RSD unsuitable for monitoring the status of abandoned peat extraction sites given the accuracy requirements. The principal issue with these and similar spectral data is that patches of bare peat are often confused with hydrophilic vegetation and other vegetation types with a lower risk of fire.

To assess fire risk and the effectiveness of rewetting abandoned peatlands, multispectral imagery with an SWIR band and a spatial resolution higher than $30 \mathrm{~m}$ is required. In the studied dataset, these criteria aligned with the Spot- 5 and Sentinel-2 data that had a $10 \mathrm{~m}$ resolution in the presence of an SWIR band with a $20 \mathrm{~m}$ resolution. To provide an assessment at the regional scale, from administrative districts and above, the combination of multispectral satellite data with a high resolution and wide coverage is required. In most cases, and especially for retrospective analyses, the most similar RSD from different scanners will need to be combined.

The results of the study demonstrate the possibility of obtaining long-term analyses of the fire hazard and tracking the results of rewetting and restoration in abandoned peatlands based on freely available Landsat, Sentinel, and commercial Spot RSD. Landsat-7, Landsat-8, and Sentinel-2 RSD provide the ability to analyze the current situation, and their forerunners, Landsat- 5 and Spot- 5 RSD, allow us to complete retrospective analyses. The high classification accuracy obtained using data from these sensors proves the capability of their combined use to provide the required general accuracy in the final result. Having compared the minimum distance using the Erdas Imagine and object-oriented ScanEx Image Processor methods, we obtained similar results, meaning that the transition from one software package to the other without quality loss is possible.

The proposed and tested approach can be used to analyze the status of abandoned and rewetted peatlands in other locations for the purposes of taking inventory, prioritizing sites subject to rewetting and restoration, monitoring changes, and assessing the efficacy of rewetting activities. The comparability of the data obtained from different sensors enables the combination of classified images, adding functionality to the time series analysis. The method developed could provide a more effective use of satellite RSD to help assess and monitor conditions and the fire hazard status of abandoned peatlands; to prioritize areas for rewetting; to evaluate areas used to bind GHG emissions, factors, and carbon data; and to evaluate the rewetting effectiveness of both fire prevention and GHG assessments.

Author Contributions: A.S., M.M., and A.M. designed the research; M.M. performed the processing of satellite data selected and prepared by A.M.; A.V. did most of ground-truthing work; A.S., M.M., and A.M. analyzed the results; and all authors wrote the paper.

Acknowledgments: The study was supported by the project "Restoring peatlands in Russia-for fire prevention and climate change mitigation" financed under the International Climate Initiative (IKI) by the German Federal Ministry for the Environment, Nature Conservation, Building and Nuclear Safety (BMUB), facilitated through KfW, project no. 11 III 040 RUS K Restoring Peatlands was also supported by the Russian Fund for Basic Research, project 15-05-07762. The authors express their gratitude to the ScanEx Group for their commitment and friendliness in providing remote sensing data, as well as to the Meschera National Park for many years of professional advice and understanding. The authors are grateful to J. Bednar (Wetlands International, the Netherlands) for his help in editing the manuscript and five anonymous reviewers of the paper for valuable comments and suggestions.

Conflicts of Interest: The authors declare no conflict of interest.

\section{Appendix A}

Class 1 "Bare peat" —areas of bare and burned peat, including patches with sparse vegetation cover. This category includes burned-out areas of different ages, as well as milled peat fields with a remaining peat layer $0.5-3.5 \mathrm{~m}$ deep. Ground water level (GWL) can be $50 \mathrm{~cm}$ and deeper. Sporadic birches and cotton-grass hummocks could occur, as well as areas with vegetation cover forming slowly on bare peat. For example, small birch reed-willow herb, willow herb, and cotton grass-small reed-moss in combination with bare peat. Moss-covered areas are dominated by 
Marchantia polymorpha and Polytrichum juniperinum, partly covered by vegetation by up to 20-30\%. As the vegetation cover density increases, this area type turns into class 2.
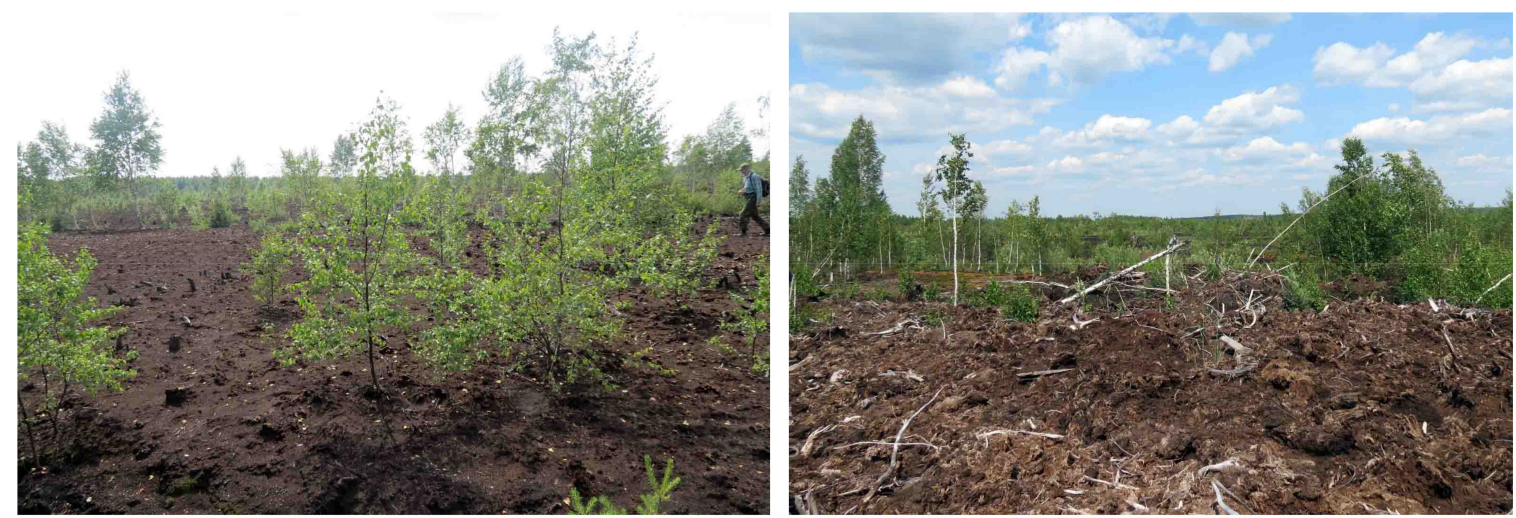

Figure A1. Test site with class 1 vegetation cover: bare peat.

Class 2 "Grass"-willow herb, small reed, and small birch reed communities. Forms during the overgrowth of bare and burned peat. These are small birch reed-willow herb, willow herb, cotton grass-willow herb-moss, grass-herb, and reed-herb groups. In the moss layer, Marchantia polymorpha and Polytrichum juniperinum are predominant. Secondarily, growing birch and willow occur, with heights not usually more than $1 \mathrm{~m}$, and rarely up to $2 \mathrm{~m}$, such as a site with a birch-moss community with bushes of Salix cinerea (willow), Carex lasiocarpa (sedge), and Calamagrostis epigeios (small reed). GWL was lower than $20 \mathrm{~cm}$. However, wet hollows with a GWL of 0-10 cm with cattail and small beds of Sphagnum cuspidatum often occur. Extremely dry (GWL up to $100 \mathrm{~cm}$ and more) and poor sites are characterized by small birch reed-willow herb communities with Betula pubestes, Calamagrostis epigeios, and Chamaerion angustifolium (undersized secondarily growing birches, height $90-140 \mathrm{~cm}$, diameter $0.6-0.9 \mathrm{~cm}$ ). Wetter sites (GWL $10 \mathrm{~cm}$ ) are characterized by cotton grass-moss communities, and Eriophorum vaginatum and Polytrichum juniperinum communities.
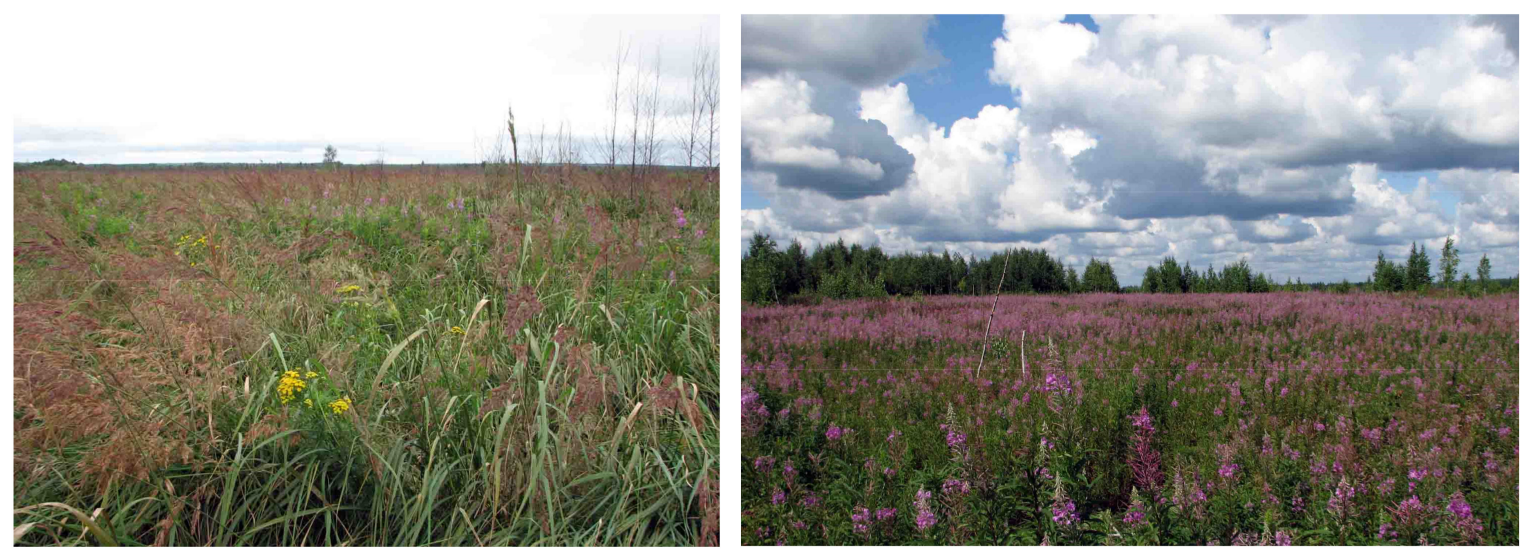

Figure A2. Test site with class 2 vegetation cover: willow herb, small reed, and small birch communities.

Class 3 "Pine"-communities with pine. Differently depressed pine stands, typically found in sites with hand and excavating peat extraction, such as two sites with excavating sod peat extraction with Pinus sylvestris, Ledum palustre, Sphagnum fallax, and Pinus sylvestris with Betula pubescens-Ledum palustre and Vaccinium vitis-idaea communities (GWL 15-25 cm); or sites with Pinus sylvestris, Eriophrum vaginatum, and Sphagnum magellanicum communities (GWL 7-10 cm). 
Often covered pit sites. These communities are typical for Central Russian mires. They could serve as an example of naturally recovered ecosystems. This category also includes peatlands drained for forestry, including pine stands with cotton grass-sphagnum, cowberry pine forests, brown moss pine forests, and pine cultures $30-45$ years old.
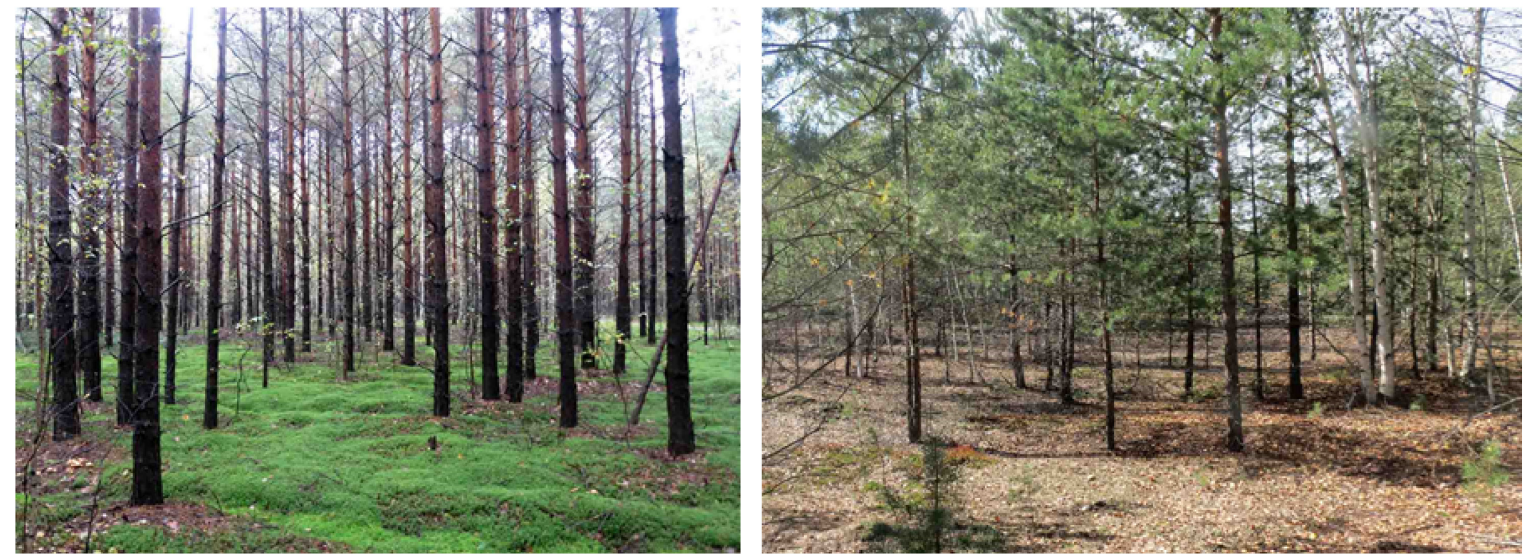

Figure A3. Test site with class 3 vegetation cover: communities with pine.

Class 4 "Willow-Birch"-communities dominated by willow and birch. Mainly birch communities that are overgrowing milled fields, occasionally with alder and aspen stands. Often forming along peatland edges, they later expand inside a peatland. Here, birch-willow herb and bush-willow herb communities are often forming. This category also includes wet black alder forests, such as a forest site with a black alder herb community. Tree stands are represented by black alder (Alnus glutinosa) (height 10-15 m, diameter 10-15 cm) with some pines and birches (seven black alders, three birches, and one pine). The undergrowth is usually mountain ash and buckthorn. Another example is a birch-moss (Betula pubestes and Polytrichum commune) community, typical for recovering post-fire succession. In the central parts of milled fields, birch-willow-small reed and birch-willow communities usually develop (GWL $20 \mathrm{~cm}$ ).
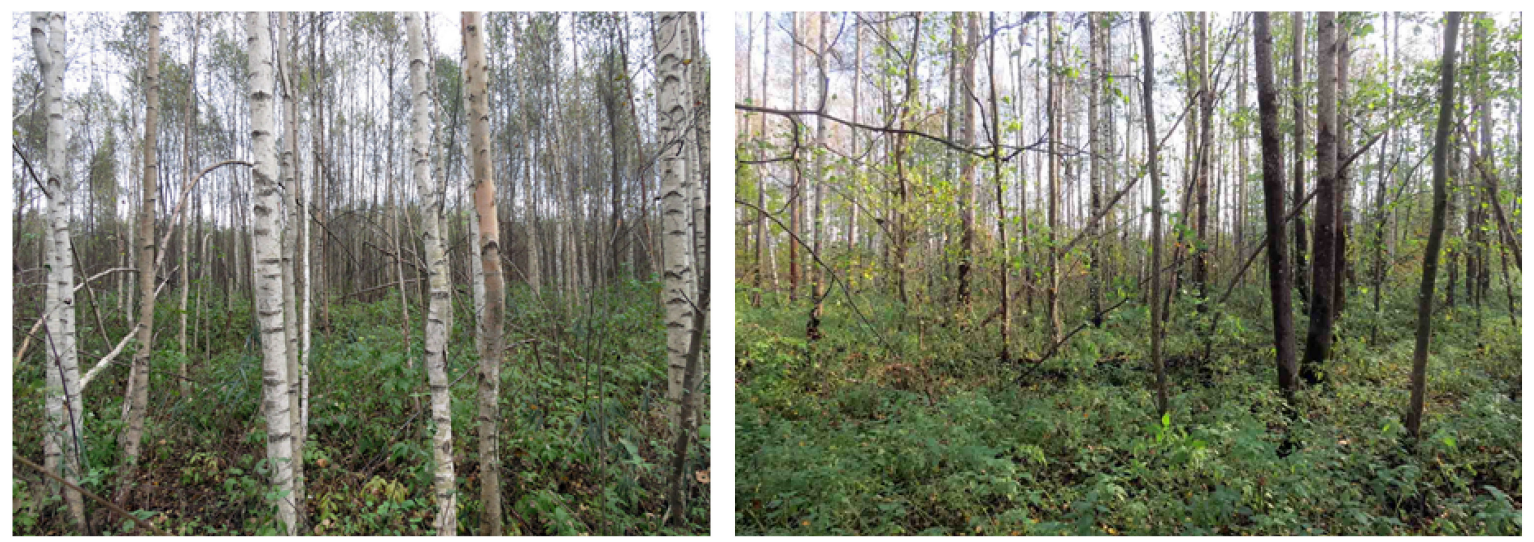

Figure A4. Test site with class 4: communities dominated by willow and birch.

Class 5 "Hydrophilic" —hydrophilic communities with cattail and reed. Formed by hydrophilic species such as cattail, reed, water plantain, and different cotton grasses in wet areas. Often, these communities are formed along banks of artificial water bodies during their overgrowth period, such as cattail (Typha angustifolia, Scripus sylvaticus) or reed (Phragmites australis) and wood club-rush (Scripus sylvaticus) communities with a GWL of 0-10 cm. Communities in this category are formed in lower waterlogged 
areas of milled fields with a GWL from 0 to $5 \mathrm{~cm}$. Most typical for milled fields are cattail-sedge, sedge-moss (Carex rostrata and Warnstorfia fluitansi) (GWL 0-15 cm), Typha angustifolia and Carex cinerea, reed-cotton grass (Phragmines australis-Eriophorum polystation) (GWL 0-5 cm), reed-cotton grass-moss (Phragmites australis-Eriophorum vaginatum-Polytrichum commune) (GWL 0-5 cm) communities. If ecological conditions remain, sphagnum mire communities could form here.
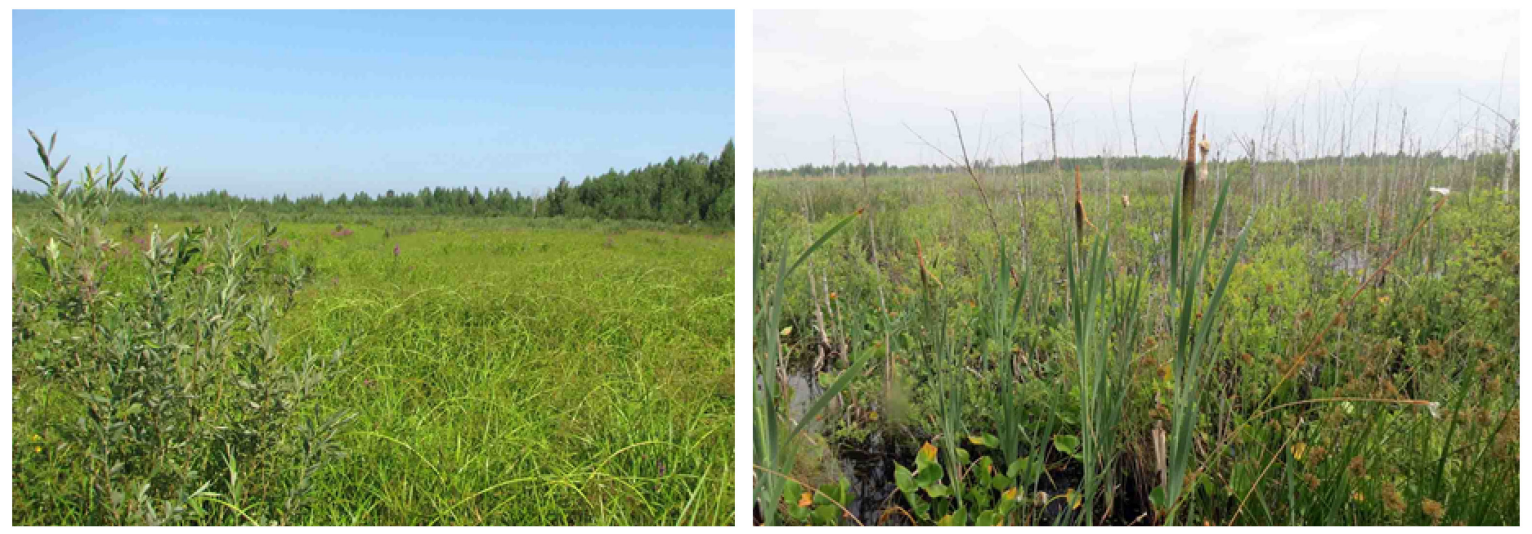

Figure A5. Test site with class 5: hydrophilic communities with cattail and reed.

Class 6 "Water" - water bodies, including those formed after natural or artificial rewetting of peatland areas. Before rewetting, willow bushes and grass vegetation grow. After rewetting, the land may remain in narrow strips with willow bushes and grass vegetation (Salix cinerea-Typha angustifolia). The water surface can be covered by duckweed (Lemna minor) and areas with cattail (Typha angustifolia), reed (Phragmites australis), and cowberry (Comarum palustre). Water depth is $0.5-1 \mathrm{~m}$ or more. Banks are often gentle, with maximum depths in the center of water bodies. This category could include previously flooded pits of hydro-peat extraction with a depth of $1 \mathrm{~m}$ or more. In vegetation covered areas, mostly cowberry (Comarum palustre), cattail (Typha angustifolia), rushes (Juncus conglomeratus, Juncus effuses), reed (Phragmites australis), duckweed (Lemna minor), and calla (Calla palustris) can be found. Banks are usually steep and overgrowth starts there.
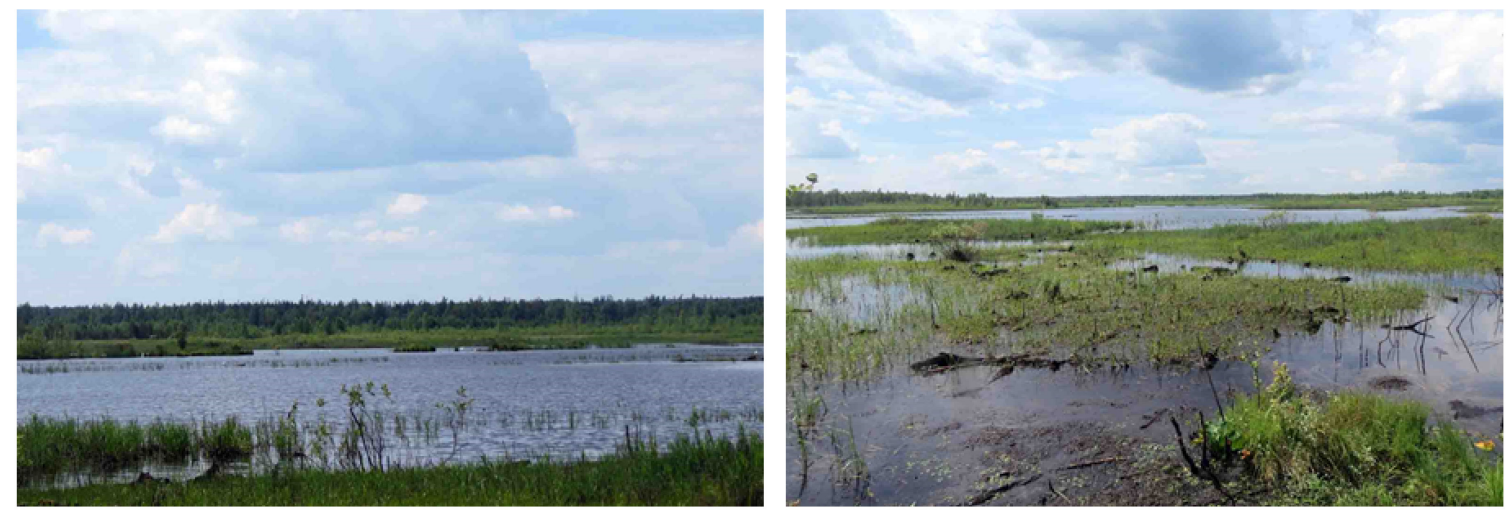

Figure A6. Test site with class 6: water.

Classes 1 and 2 have the following features: the deepest ground water levels, an intermittently drying soil surface, and the greatest fire hazard. Classes 3 and 4 are the intermediate classes. They are mainly sites covered with forest vegetation, making them prone to forest and peat fires. Rewetting these sites is generally undesirable, because it would kill the tree vegetation and result in a buildup of 
flammable material. With ground water levels close to the soil surface, Class 5 does not pose a fire danger. Classes 5 and 6 are areas to be developed into wetlands.

\section{References}

1. Joosten, H.; Clarke, D. Wise Use of Mires and Peatlands-Background and Principles Including a Framework for Decision-Making; International Mire Conservation Group: Greifswald, Germany, 2002; International Peat Society: Jyvaskyla, Finland, 2002; 303p.

2. Parish, F.; Sirin, A.; Charman, D.; Joosten, H.; Minayeva, T.; Silvius, M.; Stringer, L. (Eds.) Assessment on Peatlands, Biodiversity and Climate Change; Main Report; Global Environment Centre, Kuala Lumpur and Wetlands International: Wageningen, The Netherlands, 2008; 179p.

3. Joosten, H.; IMCG Global Peatland Database. Technical Report. International Mire Conservation Group. 2004. Available online: http:/ / www.imcg.net/pages/publications/imcg-materials.php (accessed on 2 June 2018).

4. Gorham, E. Northern peatlands: Role in the carbon cycle and probable responses to climatic warming. Ecol. Appl. 1991, 1, 182-195. [CrossRef] [PubMed]

5. Strack, M. (Ed.) Peatlands and Climate Change; International Peat Society, Saarijärven Offset Oy: Saarijärvi, Finland, 2008; 223p.

6. Yu, Z.C. Northern peatland carbon stocks and dynamics: A review. Biogeosciences 2012, 9, 4071-4085. [CrossRef]

7. Intergovernmental Panel on Climate Change (IPCC). 2013 Revised Supplementary Methods and Good Practice Guidance Arising from the Kyoto Protocol; Hiraishi, T., Krug, T., Tanabe, K., Srivastava, N., Baasansuren, J., Fukuda, M., Troxler, T.G., Eds.; IPCC: Geneva, Switzerland, 2014.

8. Wilson, D.; Blain, D.; Couwenberg, J.; Evans, C.D.; Murdiyarso, D.; Page, S.E.; Renou-Wilson, F.; Rieley, J.O.; Sirin, A.; Strack, M.; et al. Greenhouse gas emission factors associated with rewetting of organic soils. Mires Peat 2016, 17, 1-28. [CrossRef]

9. Granath, G.; Moore, P.A.; Lukenbach, M.C.; Waddington, J.M. Mitigating wildfire carbon loss in managed Northern peatlands through restoration. Sci. Rep. 2016, 6, 28498-28507. [CrossRef] [PubMed]

10. Minayeva, T.Y.; Sirin, A.A. Peatland Biodiversity and Climate Change. Biol. Bull. Rev. 2012, 2, 164-175. [CrossRef]

11. Minayeva, T.; Bragg, O.; Sirin, A. Peatland biodiversity and its restoration. In Peatland Restoration and Ecosystem Services: Science, Policy and Practice; Cambridge University Press: Cambridge, UK, 2016; pp. 47-65.

12. Minayeva, T.Y.; Bragg, O.M.; Sirin, A.A. Towards ecosystem-based restoration of peatland biodiversity. Mires Peat 2017, 19, 1-36. [CrossRef]

13. Joosten, $\mathrm{H}$. The Global Peatland $\mathrm{CO}_{2}$ Picture: Peatland Status and Drainage Related Emissions in All Countries of the World; Wetlands International: Wageningen, The Netherlands, 2010; p. 36. Available online: https: // www.wetlands.org/publications/the-global-peatland-CO2-picture/ (accessed on 2 June 2018).

14. Vompersky, S.E.; Ivanov, A.I.; Tsyganova, O.P.; Valyaeva, N.A.; Dubinin, A.I.; Glukhov, A.I.; Markelova, L.G. Bog Organic Soils and Bogs of Russia and Carbon Pool of Their Peats. Eur. Soil Sci. 1996, 28, 91-105.

15. Vompersky, S.E.; Sirin, A.A.; Tsyganova, O.P.; Valyaeva, N.A.; Maikov, D.A. Peatlands and Paludified Lands of Russia: Attempt of Analyses of Spatial Distribution and Diversity. Izvesfiya Ross. Akad. Nauk Ser. Geogr. 2005, 5, 21-33. (In Russian)

16. Vompersky, S.E.; Sirin, A.A.; Salnikov, A.A.; Tsyganova, O.P.; Valyaeva, N.A. Estimation of Forest Cover Extent over Peatland and Paludified Shallow Peatlands in Russia. Contemp. Probl. Ecol. 2011, 4, 734-741. [CrossRef]

17. Sirin, A.A.; Minaeva, T.J. (Eds.) Peatlands of Russia: Towards Analysis of Sectorial Information; GEOS Public: Moscow, Russia, 2001; p. 205. (In Russian)

18. Tanneberger, F.; Tegetmeyer, C.; Busse, S.; Barthelmes, A.; Shumka, S.; Mariné, A.M.; Jenderedjian, K.; Steiner, G.M.; Essl, F.; Etzold, J.; et al. The peatland map of Europe. Mires Peat 2017, 19, 1-17. [CrossRef]

19. Sirin, A.; Minayeva, T.; Yurkovskaya, T.; Kuznetsov, O.; Smagin, V.; Fedotov, Y.U.; Russian Federation (European Part). Mires and Peatlands of Europe: Status, Distribution and Conservation; Joosten, H., Tanneberger, F., Moen, A., Eds.; Schweizerbart Science Publishers: Stuttgart, Germany, 2017; pp. 589-616.

20. Minayeva, T.; Sirin, A.; Bragg, O.A. (Eds.) Quick Scan of Peatlands in Central and Eastern Europe; Wetlands International: Wageningen, The Netherlands, 2009; p. 132. 
21. Minayeva, T.; Sirin, A. The Peat Fires-The causes and the prevention ways. Sci. Ind. Russ. 2002, 9, 3-8. (In Russian)

22. Sirin, A.; Minayeva, T.; Vozbrannaya, A.; Bartalev, S. How to avoid peat fires? Sci. Russ. 2011, 2, $13-21$.

23. Minayeva, T.; Sirin, A.; Stracher, G.B. The Peat Fires of Russia. In Coal and Peat Fires: A Global Perspective. V.2: Photographs and Multimedia Tours; Stracher, G.B., Prakash, A., Sokol, E.V., Eds.; Elsevier: Amsterdam, The Netherlands, 2013; pp. 375-394.

24. Safronov, A.; Fokeeva, E.; Rakitin, V.; Grechko, E.; Shumsky, R. Severe Wildfires Near Moscow, Russia in 2010: Modeling of Carbon Monoxide Pollution and Comparisons with Observations. Remote Sens. 2015, 7, 395-429. [CrossRef]

25. Sirin, A.; Maslov, A.; Medvedeva, M.; Vozbrannaya, A.; Valyaeva, N.; Tsyganova, O.; Glukhova, T.; Makarov, D. Multispectral Remote Sensing Data as a Tool for Assessing the Need and the Effectiveness for Peatland Restoration. In Proceedings of the 9th European Conference on Ecological Restoration, Oulu, Finland, 3-8 August 2014; Tolvanen, A., Hekkala, A.M., Eds.; Finnish Forest Research Institute: Oulu, Finland, 2014; p. 133.

26. Dronova, I. Object-Based Image Analysis in Wetland Research: A Review. Remote Sens. 2015, 7, 6380-6413. [CrossRef]

27. White, L.; Brisco, B.; Dabboor, M.; Schmitt, A.; Pratt, A. A Collection of SAR Methodologies for Monitoring Wetlands. Remote Sens. 2015, 7, 7615-7645. [CrossRef]

28. Lin, Y.; Liquan, Z. Identification of the spectral characteristics of submerged plant Vallisneria spiralis. Acta Ecol. Sin. 2006, 26, 1005-1011. [CrossRef]

29. Adam, E.; Mutanga, O. Spectral discrimination of papyrus vegetation (Cyperus papyrus L.) in swamp wetlands using field spectrometry. ISPRS J. Photogramm. Remote Sens. 2009, 64, 612-620. [CrossRef]

30. Crichton, K.A.; Anderson, K.; Bennie, J.J.; Milton, E.J. Characterizing peatland carbon balance estimates using freely available Landsat ETM plus data. Ecohydrology 2015, 8, 493-503. [CrossRef]

31. Knox, S.H.; Dronova, I.; Sturtevant, C.; Patricia, Y.; Oikawa, P.Y.; Matthes, J.H.; Verfaillie, J.; Baldocchia, D. Using digital camera and Landsat imagery with eddy covariance data to model gross primary production in restored wetlands. Agric. For. Meteorol. 2017, 237, 233-245. [CrossRef]

32. Yanovskiy, A.A. Remote Assessment of the Spectral Reflectance of a Surface of the Drained Peat Soils of Polesye on the Basis of Satellite Images of Medium Spatial Resolution. Issled. Zemli Kosmosa 2017, 5, 35-48. [CrossRef]

33. Medvedeva, M.A.; Vozbrannaya, A.E.; Bartalev, S.A.; Sirin, A.A. Multispectral remote sensing for assessing changes on abandoned peat extraction lands. Issled. Zemli Kosmosa 2011, 5, 80-88. (In Russian)

34. Antipin, V.K.; Boytchuk, M.A.; Grabovik, S.I. Vegetation cover of natural and utilized peat bogs of the National Park "Meschera", Vladimir Region. In Proceedings of the International Scientific Conference on Anthropogenic Transformation of Boreal Ecosystems of Europe: Ecological, Resource and Economic Aspects, Petrozavodsk, Russia, 23-25 November 2004; pp. 166-169. (In Russian)

35. Antipin, V.K.; Boychuk, M.A.; Grabovik, S.I.; Stoykina, N.V. Modern structure and restoration of mire biota of National Park "Meschera", Vladimir Oblast. Tver State Technical University. Trudy Instorfa Sci. J. 2013, 8,11-17. (In Russian)

36. Vozbrannaya, A.E.; Antipin, V.K.; Sirin, A.A. Monitoring of Vegetation Cover and Ecological Conditions of Disturbed Peatlands of State National Park "Meschara" in Vladimir Region. In Proceedings of the International Scientific Conference on Vegetation Monitoring and Assessment, Minsk, Belarus, 22-26 September 2008; pp. 244-246. (In Russian)

37. Clevers, J.G.P.W.; Gitelson, A.A. Remote estimation of crop and grass chlorophyll and nitrogen content using red-edge bands on Sentinel-2 and -3. Int. J. Appl. Earth Obs. Geoinf. 2013, 23, 344-351. [CrossRef]

38. Olofsson, P.; Foody, G.M.; Herold, M.; Stehman, S.V.; Woodcock, C.E.; Wulder, M.A. Good practices for estimating area and assessing accuracy of land change. Remote Sens. Environ. 2014, 148, 42-57. [CrossRef]

39. Pearson, K. Mathematical Contributions to the Theory of Evolution. XIII. On the Theory of Contingency and Its Relation to Association and Normal Correlation; Drapers' Company Research Memoirs Biometric Series; Drapers' Company: London, UK, 1904; pp. 1-35.

40. Scan Ex. Remote Sensing Data Processing Program Scan Ex Image Processor v.4.2. Remote Sensing Data Thematic Interpretation Module Thematic Pro, In User's Guide 2014. Available online: http: / / new.scanex. ru/upload/iblock/7b7/7b760146c691873ff8580321cc1c5420.pdf (accessed on 18 May 2018). 
41. Immitzer, M.; Vuolo, F.; Atzberger, C. First Experience with Sentinel-2 Data for Crop and Tree Species Classifications in Central Europe. Remote Sens. 2016, 8, 166-193. [CrossRef]

42. Medvedeva, M.A.; Vozbrannaya, A.E.; Sirin, A.A.; Maslov, A.A. Capabilities of Multispectral Remote-Sensing Data in an Assessment of the Status of Abandoned Fire Hazardous and Rewetting Peat Extraction Lands. Izvestiya Atmos. Ocean. Phys. 2017, 53, 1070-1078. [CrossRef]

43. Berberoglu, S.; Akin, A. Assessing different remote sensing techniques to detect land use/cover changes in the eastern Mediterranean. Int. J. Appl. Earth Obs. Geoinf. 2009, 11, 46-53. [CrossRef]

44. McGovern, E.A.; Holden, N.M.; Ward, S.M.; Collins, J.F. Remotely sensed satellite imagery as an information source for industrial peatlands management. Resour. Conserv. Recycl. 2000, 28, 67-83. [CrossRef]

45. Achard, F.; Grassi, G.; Herold, M.; Teobaldelli, M.; Mollicone, D. (Eds.) Use of satellite remote sensing in LULUCF sector. GOFLCD. In IPCC Guidance on Estimating Emissions and Removals of Greenhouse Gases from Land Uses such as Agriculture and Forestry; Land Cover Project Office: Jena, Germany, 2008; pp. 1-25.

46. Sirin, A.A.; Maslov, A.A.; Valyaeva, T.A.; Tsyganova, O.P.; Glukhova, T.V. Mapping of Peatlands in the Moscow Oblast Based on High Resolution Remote Sensing Data. Contemp. Probl. Ecol. 2014, 7, 809-815. [CrossRef]

47. O'Connell, J.; Connolly, J.; Holden, N.M. A monitoring protocol for vegetation change on Irish peatland and heath. Int. J. Appl. Earth Obs. Geoinf. 2014, 31, 130-142. [CrossRef]

(C) 2018 by the authors. Licensee MDPI, Basel, Switzerland. This article is an open access article distributed under the terms and conditions of the Creative Commons Attribution (CC BY) license (http://creativecommons.org/licenses/by/4.0/). 